\title{
THE INFLUENCE OF WORLD KNOWLEDGE ON PROJECTIVITY
}

LISTENERS REVISE THEIR GENDER STEREOTYPES WHEN PROCESSING PRESUPPOSITIONS TRIGGERED BY stop

\section{AlexANDRA LORSON \\ The University of Potsdam}

Department of Linguistics

FSS 2018

1st Supervisor: Prof. Dr. Titus von der Malsburg

2nd Supervisor: Prof. Dr. Malte Zimmermann

17th June 2021

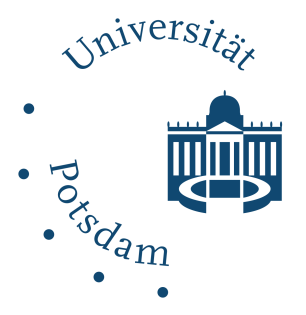




\section{Selbstständigkeitserklärung}

Ich versichere, dass ich die eingereichte Masterarbeit selbständig, ohne fremde Hilfe angefertigt und keine anderen als die angegebenen Quellen und Hilfsmittel benutzt habe. Passagen der Arbeit, die dem Wortlaut oder dem Sinn nach anderen Werken entnommen wurden, habe ich unter genauer Angabe der Quelle deutlich als Zitat kenntlich gemacht. Diese Arbeit war in gleicher oder ähnlicher Fassung noch nicht Bestandteil einer Studien- oder Prüfungsleistung bzw. lag einer anderen Prüfungsbehörde bereits vor.

Ort, Datum

Unterschrift 


\begin{abstract}
The change of state verb stop is known to trigger a pre-state presupposition of the form ' $\mathrm{X}$ used to V'. However, confronted with a question such as Did David stop dancing ballet?, listeners do not necessarily understand that David used to dance ballet. Several factors seem to converge in influencing listeners' understanding of presuppositions in these so-called embedding environments, of which questions are an example. One of these factors is at-issueness (Cummins \& Rohde, 2015; Tonhauser, 2016; Tonhauser, Beaver \& Degen, 2018), the extent to which content is judged to be under debate. Another factor that was claimed to influence the processing of presuppositions was world knowledge in form of prior probabilities of events (Stevens, de Marneffe, Speer \& Tonhauser, 2017; Tonhauser et al., 2018). Following this argumentation, listeners who find that it is unlikely that David dances ballet when processing Did David stop dancing ballet?, are claimed to less likely understand that David used to dance ballet and stopped doing so.

This thesis investigated the influence of listeners' prior beliefs on their processing of presuppositions, and more specifically, in what way the understanding of presuppositions triggered by stop is influenced by gender stereotypes. Boyce, von der Malsburg, Poppels and Levy (2018) found that it is more likely that people consider a ballet dancer to be a woman rather than a man. Do listeners use this prior beliefs when they interpret utterances such as Did David stop dancing ballet?? A further aim of this thesis was to replicate Tonhauser et al. (2018)'s findings on the effect of at-issueness. Whereas the influence of at-issueness could be replicated, no evidence was found that listener's gender stereotypes affect their understanding of presuppositions. Instead, the results are in line with the hypothesis that listeners revise their prior beliefs when they are confronted with utterances that contradict their beliefs. Nonetheless, due to limitations of the experiment at hand, more research is needed to explore the possible effects of listeners' prior beliefs on their processing of presuppositions by (i) using a more fine-grained experimental design, and (ii) by exploring more aspects of listeners' world knowledge.
\end{abstract}




\section{Zusammenfassung in Deutscher Sprache}

Diese Masterarbeit handelt vom sogenannten Projektionsproblem: die Schwierigkeit das Projektionsverhalten von Präsuppositionen zu formalisieren und vorherzusagen. Das heißt Präsuppositionen sind, anders als semantische Implikationen, nicht von Negation oder Frageoperatoren betroffen. Beispiel (1a) vermittelt nicht nur die vordergründige Aussage, dass Jessica aufgehört als Nanny zu arbeiten, sondern auch die Präsupposition, dass Jessica mal als Nanny gearbeitet hat. Diese Präsupposition wird ebenso in Beispiel (1b) ausgelöst, obwohl hier der vordergründige Inhalt, dass Jessica aufgehört hat als Nanny zu arbeiten, fraglich ist. Demnach projiziert die Präsupposition über den Frageoperator, und nur Jessica's Aufhören ist von diesem betroffen.

(1) a. Jessica stopped working as a nanny. Jessica hat aufgehört als Kindermädchen zu arbeiten.

b. Did Jessica stop working as a nanny? Hat Jessica aufgehört als Kindermädchen zu arbeiten?

Allerdings verstehen Zuhörer nicht notwendiger Weise, dass Jessica mal als Nanny gearbeitet hat. In Beispiel (2) ist 'Jessica' prosodisch markiert (gekenzeichnet durch Großschreibung), und eine übergeordnete Diskursfrage der Form Wer war es der aufgehört hat als Nanny zu arbeiten? wird signalisiert. Dementsprechend war es nicht zwingenderweise Jessica, die aufgehört hat als Nanny zu arbeiten, es hätte auch jemand anderes sein können.

(2) Did JESSICA stop working as a nanny?

Hat JESSICA aufgehört als Kindermädchen zu arbeiten?

Forschung die sich mit dem Projektionsverhalten von Präsuppositionen beschäftigt ist an der Schnittstelle von Pragmatik und Semantik anzusiedeln. Demnach sind linguistische Ansätze, die sich mit der Projektion von Präsuppositionen beschäftigen sehr vielseitig. Nichts desto trotz ist es weitgehend etabliert, dass das Verstehen von in Fragen eingebetteten Präsuppositionen von unterschiedlichen Faktoren abhängt, wie zum Beispiel Diskursstruktur. Einer der bisher noch nicht erforschten Faktoren, welcher das Interpretieren von Präsuppositionen beeinflussen könnten ist das Weltwissen der Zuhörer (Stevens et al., 2017; Tonhauser et al., 2018).

Diese Masterarbeit befasst sich mit der Präsupposition von stop und der Frage wie Zuhörer ihr Weltwissen nutzen, um diese Präsupposition zu interpretieren. Dabei wurde sich ausschließlich mit dem Einfluss von Geschlechter Stereotypen beschäftigt, die man bei Amerikanisch Englischen Sprechern festgestellt hat (Boyce et al., 2018). Darüber hinaus wurde versucht den bereits gefundenden Effekt von Diskursstruktur auf das Projektionsverhalten von Präsuppositionen zu replizieren (Tonhauser et al., 2018). Zu diesem Zweck wurde die Präsupposition, ausgelöst vom englischen Verb 
stop untersucht unter der Fragestellung, ob die Wahrscheinlichkeit, dass eine Präsupposition projiziert höher ist, wenn ihr Inhalt mit Geschlechterstereotypen übereinstimmt. Zum Beispiel wurde festgestellt, dass Amerikanisch Englische Sprecher den Beruf des Kindermädchens ('Nanny') mit einer Wahrscheinlichkeit von 0.8 als weiblichen Beruf assoziieren (Boyce et al., 2018). Ist es deshalb also wahrscheinlicher, dass die Präsupposition in (43b) projiziert als die Präsupposition in (3), da es laut Sprechern unwahrscheinlicher ist, dass Sebastian den Beruf des Kindermädchens ausübt, als Jessica?

(3) Did Sebastian stop working as a nanny?

Hat Sebastian aufgehört als Kindermädchen zu arbeiten?

Die Entscheidung das Projektionsverhalten von Präsuppositionen ausgelöst von stop eingehender zu untersuchen, basiert auf der Feststellung, dass Diskursstruktur nur bedingt das Projektionsverhalten von stop vorhersagen kann. Zudem ist das Projektionsverhalten von stop generell ein viel diskutierter Fall in der theoretischen Linguistik, speziell in den Feldern der Semantik und Pragmatik, da es nicht klar ist wie anfällig die Präsupposition von stop gegenüber Einflussfaktoren wie Diskursstruktur überhaupt ist. Diese Debatte spiegelt sich auch in sich widersprechenden Resultaten zum Projektionsverhalten von stop in der empirischen Forschung wider. Daher bleibt zu ermitteln, ob es noch weitere bislang unerfroschte Einflussfaktoren gibt. Der Einfluss von Weltwissen in Form von a priori Wahrscheinlichkeiten auf das Projektionsverhalten von Präsuppositionen ist so noch nicht untersucht worden.

Neben der Relevanz für die Bereiche der Semantik und Pragmatik ist die hier untersuchte Fragestellung höchst relevant für eine kürzlich etablierte Forschungsausrichtung innerhalb des Rational Speech Act frameworks (Goodman \& Stuhlmüller, 2012), welche Sprachverstehen als Bayesianische Inferenz untersucht. Ein definierendes Kennzeichnen dieses Ansatzes ist das Einkalkulieren

von Ansichten, die Zuhörer a priori haben bevor sie eine Äußerung interpretieren. Diese Art von Weltwissen ist allgemein in Form von Wahrscheinlichkeiten die Zuhörer mit bestimmten Interpretationen assoziieren, untersucht worden. Welche Rolle Geschlechterstereotypen hierbei spielen, bleibt noch zu ermitteln.

Während der Effekt von Diskursstruktur repliziert werden konnte, konnte kein Effekt von Weltwissen in Form von Geschlechterstereotypen nachgewiesen werden. Das bedeutet, dass Zuhörer ihre starken Ansichten in Bezug auf Berufe wie 'Nanny' revidierten, sobald sie mit Äußerungen wie in Beispiel (3) konfrontiert wurden. Neben dieser Möglichkeit, weist die starke Variabilität in den Daten darauf hin, dass ein ausgefeilteres experimentelles Design nötig ist, um mögliche Effekte von Weltwissen festzustellen. 


\section{Acknowledgement}

I would first like to thank my first thesis advisor Titus von der Malsburg for his constant support. Our discussions have always been very inspiring and contributed a lot to the general subject of this thesis and its empirical part.

Additionally, I would like to thank my second thesis advisor Malte Zimmermann who was a great help in all theoretical questions that came up. I would also like to acknowledge the financial support of the University of Potsdam without which the wide scope of my study would not have been possible.

Furthermore, I would like to thank my family and friends who have lent (knowingly and unknowingly) their names to my examples. All of them helped me in their own way during the last year. Thank you all very much!

Alexandra Lorson 


\section{Contents}

1 Introduction $\quad 1$

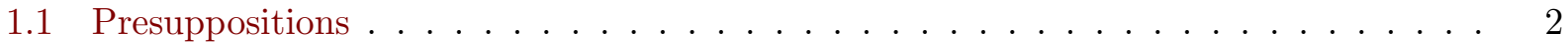

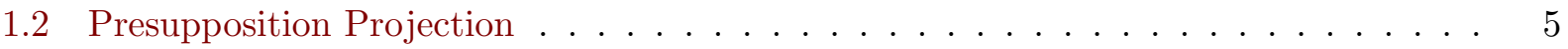

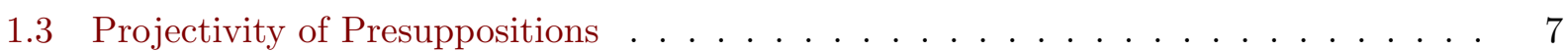

2 Predicting Projection $\quad 9$

2.1 Local Contexts . . . . . . . . . . . . . . . . . . . . . . 10

2.1.1 Global and local accommodation . . . . . . . . . . . . . . . . 10

2.1.2 Global versus local accommodation . . . . . . . . . . . . . . . . 13

2.2 Discourse Structure . . . . . . . . . . . . . . . . . . . . . . 15

2.2 .1 At-issueness and the QUD . . . . . . . . . . . . . . 15

2.2 .2 Investigating at-issueness . . . . . . . . . . . . . . . . . 19

2.3 Attention and variability . . . . . . . . . . . . . . . . 22

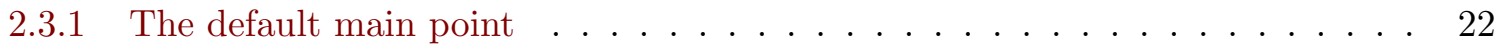

2.3.2 The secondary main point . . . . . . . . . . . . . 24

2.3 .3 All in one! . . . . . . . . . . . . . . . . . . . . 27

2.4 World knowledge . . . . . . . . . . . . . . . . . . . 29

2.4.1 The Rational Speech Act model _ . . . . . . . . . . . . . . . . . . . 29

2.4 .2 Prior beliefs . . . . . . . . . . . . . . . . . . . 32

3 Empirical Part $\quad 35$

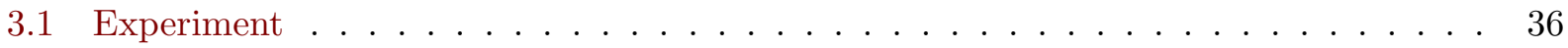

3.1 .1 Gender stereotypes . . . . . . . . . . . . . . . . . . . . . . . . . . . . .

3.1 .2 Design . . . . . . . . . . . . . . . . . . . . 37

3.1 .3 Materials . . . . . . . . . . . . . . . . . . . . 38

3.1.4 Participants and Procedure . . . . . . . . . . . . . . . . 42

3.2 Results. . . . . . . . . . . . . . . . . . . . . . . 43 
3.2.1 Projection variability across contents . . . . . . . . . . . . . . . 43

3.2 .2 At-issueness and Consistency . . . . . . . . . . . . . . . 46

3.2 .3 Bayesian Analysis . . . . . . . . . . . . . . . . . . . 47

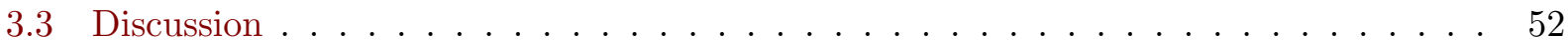

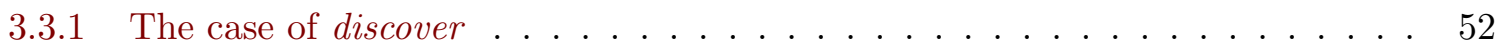

3.3 .2 Extreme prior probabilities . . . . . . . . . . . . . 54

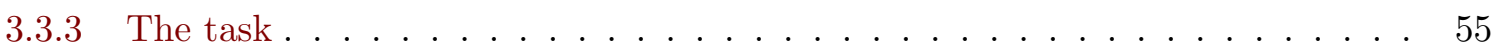

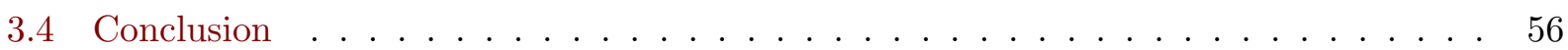

$\begin{array}{ll}\text { Abbreviations } & 58\end{array}$

$\begin{array}{ll}\text { Appendix } & 61\end{array}$

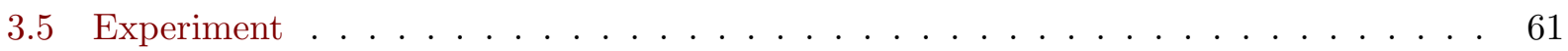

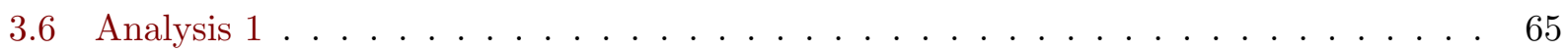

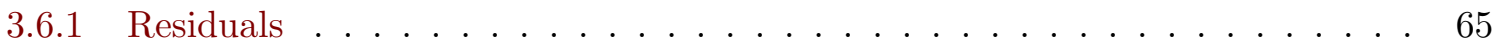

3.6 .2 Normality of random effects . . . . . . . . . . . . . . . . . . . . . . . . . 66

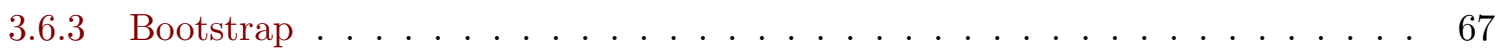

References

List of Tables $\quad$ v

List of Figures 


\section{Chapter 1}

\section{Introduction}

This thesis is about the so-called projection problem, i.e. the problem of formalising and predicting the projection behaviour of presuppositions. ${ }^{1}$ Presupposition projection refers to the phenomenon whereby presuppositions are often unaffected by entailment-cancelling operator, such as negation, or polar questions. An example is found in (4b), where stop is embedded under a polar question operator. Listeners understand the presupposition that Jessica used to work as a nanny for both utterances in (4), even though it is not clear whether she did or did not stop doing so in (4b), opposed to (4a). The presupposition is said to project over the polar question operator.

(4) a. Jessica stopped working as a nanny.

b. Did Jessica stop working as a nanny?

However, the projection behaviour of presuppositions is more complex than this, since sometimes presuppositions are affected by entailment-cancelling operators. One straightforward way to prevent a presupposition to arise was found to be discourse structure. For example in (5), where 'Jessica' is prosodically marked, a discourse question of the form Was it Jessica who stopped working as a nanny? is signalled. Thus, it was not necessarily Jessica who may or may not have stopped working as a nanny. Consequently, listeners may understand that it was someone other than Jessica who used to work as nanny. In this example (5), then, the presupposition that Jessica used to work as a nanny is not necessarily implied.

(5) Did JESSICA stop working as a nanny?

Since presupposition projection is a phenomenon at the semantics-pragmatics interface, approaches on projection are very diverse. Nevertheless, it is fairly established that there are several factors

\footnotetext{
${ }^{1}$ This thesis is not about the triggering problem, i.e. the question of whether presuppositions are triggered conventionally or conversationally. It will be assumed that, in order to discuss the projection problem, it is not necessary to make a claim about the triggering mode of presuppositions.
} 
that may influence projection. Besides local context, discourse structure, and presupposition trigger type, one factor that was only claimed, but not yet investigated to influence projection behaviour is world knowledge. The aim of this thesis was to investigate whether world knowledge in form of prior probabilities of events influences projection behaviour. For this purpose, the presupposition triggered by stop was examined, particularly, the extent to which gender stereotypes influence its projection behaviour: Is the probability of presuppositions to project higher when their content is likely than when their content is unlikely? For example, according to listeners' beliefs about gender stereotypes associated with occupations, Sebastian being a nanny is less likely than Jessica being a nanny. Does this mean that the presupposition in (6) is consequently less likely to project than in $(4) ?$

(6) Did Sebastian stop working as a nanny?

The decision to investigate the projection behaviour of stop and the possible influence of world knowledge is based on the observation in the literature that other factors, such as discourse structure, seem to be insufficient in predicting its projection behaviour. Moreover, the projection behaviour of stop has often been a subject of debate within theoretical linguistics which is mirrored by contradictory findings in the empirical research. Besides being highly relevant for research within the areas of experimental semantics and pragmatics, my findings will contribute to research that investigates listeners' interpretation process as Bayesian inference. A defining feature of this line of research is that world knowledge in form of prior beliefs affects listeners' inferences, a feature that helped to successfully capture a variety of linguistic phenomena. Crucially, gender stereotypes as part of listeners' prior beliefs have yet to be examined. Regarding presupposition projection, the influence of listeners' world knowledge on their assessment of speaker commitment has only been a theoretical claim but an empirical investigation is missing.

First, presuppositions will be introduced in section 1.1, together with presupposition projection in section 1.2, followed by a discussion on projection variability in section 1.3. Chapter 2 of this thesis will introduce relevant factors that have been found to influence projection behaviour, or have been proposed to do so, along with theoretical approaches and empirical findings. The focus will thereby lie on the treatment and findings on stop, and the contrast between stop and other presupposition triggers. Chapter 3 of the thesis is concerned with the experimental investigation on the influence of world knowledge and at-issueness on the projection behaviour of stop.

\subsection{Presuppositions}

In conveying information, speakers can use various strategies to foreground and background the points they are making. Some meaning is mentioned explicitly; other meaning is conveyed via 
backgrounding strategies that rely on assumptions about what listeners already know. For example, understanding sentence (7) requires interpreting one message about Simon having stopped doing Judo and another (not explicitly stated message) about Simon having done Judo in the past. The first type of meaning is called the asserted meaning; the second backgrounded type is content that the speaker presupposes and is taken to be committed to.

(7) Simon: I stopped doing Judo.

Presupposition: Simon used to do Judo.

This thesis will focus on those backgrounding strategies that are associated with lexical items, henceforth called presupposition triggers, like the change of state verb stop. The trigger stop signals a presupposition of the form ' $\mathrm{X}$ used to V', where $\mathrm{X}$ may denote an individual and $\mathrm{V}$ a habit/occupation. For example, by uttering (7), the speaker asserts that he stopped doing Judo and presupposes that he used to do Judo. Further presupposition triggers, among others, are emotive factive verbs like to be annoyed and regret, cognitive factive verbs such as know, realise and discover and iteratives like again and too. Factive verbs signal a presupposition of the form 'it is indeed true that $\mathrm{Y}$ ', where Y stands for the content of the factive's complement: in (8), the speaker presupposes the fact that Martin's research assistant has indeed called in sick.

(8) Simon: Martin discovered that his research assistant has called in sick today. Presupposition: Martin's research assistant indeed called in sick today.

Iteratives like again signal a presupposition of the form ' $\mathrm{Z}$ happened before', where $\mathrm{Z}$ denotes the prejacent of again: in (9), the speaker presupposes that Max had been to the Punk festival before.

(9) Simon: Max went to the Punk festival again.

Presupposition: Max has been to the Punk festival before.

In what follows, the term 'presupposition' will be used to denote the form of the content that is associated with a certain presupposition trigger, e.g. 'X used to V'. When talking about the specific content of a presupposition the term lexical content will be used, e.g. Simon used to do Judo. Thus, each presupposition trigger signals a specific presupposition, which in turn is instantiated by some lexical content describing an event.

The difference between presuppositions and other aspects of meaning like assertions, results from them being not the main point of an utterance, and instead, denoting background information (Levinson, 1983). Thus speakers are commonly taken to assume that the backgrounded content is already shared knowledge between them and the listeners, and 'taken for granted' (Chierchia \& McConnell-Ginet, 2000). Stalnaker (1978)'s notion of the common ground captures precisely that. The common ground is said to contain those information that is assumed to be true by the 
interlocutors of a conversation. Assertions may extend the common ground if they introduce new information, as long as they are accepted by all interlocutors. Thus, it is often said that uttering a presupposition faithfully is contextually restricted: The content of the presupposition already has to be part of the common ground. Realistically speaking, interlocutors often do not know what information they actually share, however, it still holds that they behave as if the content that they presuppose was part of the common ground. Consequently, by being presumably shared knowledge, presupposed content cannot be addressed or questioned as easily by addressees as assertions, see (10). In contrast to (10a), Simon's response in (10b) seems odd, a case where Lydia's question was understood to address the backgrounded content (Simon used to do Judo) instead of the assertion (Simon stopped doing Judo). Hence, presuppositions are generally not the topic of further discussion in the preceding conversation but commonly shared knowledge and established facts.

(10) Simon: I stopped doing Judo.

Lydia: Really?

a. Simon: Yes, I stopped.

b. Simon: ?Yes, I used to do Judo

A further characteristic of presuppositions is that they behave differently from linguistic phenomena like conversational implicatures or entailments and are thus neither a fully conversational nor a fully conventional phenomenon. Following Grice (1975), conversational implicatures arise due to pragmatic reasoning and cooperative principles of rational behaviour like telling the truth, being precise, relevant and clear. Thus, conversational implicatures are merely suggested by the context. For example, when (11) would be embedded in a context where Anna's character trades were discussed, it is conversationally implied that Anna is not more than a competent gardener, which is the only explanation that renders uttering (11) relevant for the given context. In a context where it is discussed whether to hire Anna as a gardener or not, this implicature disappears. This characteristic distinguishes presuppositions from conversational implicatures, since presuppositions don't disappear that easily, in fact, only in particular environments.

\section{(11) Anna is a competent gardener.}

Entailments on the other hand cannot be cancelled, since they establish logical relations between propositions of sentences. In (12), we have two propositions one of which is entailed by the other: that Laura broke the window entails that the window is broke (12b), i.e. whenever (12a) is true (12b) must also be true, and whenever (12a) is false (12b) must also be false.

(12) a. Laura broke the window.

b. The window is broke. 
In contrast, a case where presuppositions are false does not straightforwardly lead to the falsity of the whole sentence. Instead, going back to Strawson (1950)'s discussion on definite descriptions, sentences whose presupposition is false are often assumed to lack a truth value. For example it gets apparent for (13), taken from Schwarz (2016), that it is difficult to assign a truth value to (13a) when (13b) was false, i.e. a context where Mary never has thrown parties.

(13) a. Mary stopped throwing parties.

b. Mary used to throw parties.

In the next section, the characteristics of presuppositions will be related to their behaviour in embedding environments. It will be illustrated that (i) unlike conversational implicatures, presuppositions may only disappear in embedding environments, and (ii) that it is exactly that circumstance that tells presuppositions apart from entailments and which makes it difficult to treat them as wholly conversational or conventional phenomenon.

\subsection{Presupposition Projection}

The difference between presuppositions and other aspects of meaning becomes most apparent in so called embedding environments, i.e. when the presupposition trigger is embedded under an entailment-cancelling operator like question operators, modals, antecedents of conditionals or negation. Considering a case where (12) is either negated, see (14a), or part of a polar question, see (14b), the entailment that the window is broke does no longer hold.

(14) a. Laura didn't break the window.

b. Did Laura break the window?

c. \#The window is broke.

Related to the difference between assertions as foregrounded, and presuppositions as backgrounded content, only assertions seem affected by the entailment-canceling operator and presuppositions seem to 'escape' the operator's scope. For example in contrast to (15), Kati did NOT stop smoking and still smokes in (15a) where the presupposition trigger is negated. Nonetheless, in both cases Simon presupposes that Kati used to smoke. The same goes for example (15b) where the presupposition trigger is embedded under a polar-question operator. Whereas the assertion is under debate (Kati either did or did not stop smoking), the content about her having smoked in the past may still persist.

(15) Simon: Kati stopped smoking.

a. Simon: Kati didn't stop smoking. 


\section{b. Simon: Did Kati stop smoking?}

This behaviour is commonly known as presupposition projection: presuppositions have the potential to project over the scope of entailment-cancelling operators. Referring to the actual interaction between interlocutors, one can similarly say that speakers are still taken to be committed to the lexical content of a presupposition, even if the presupposition trigger is embedded under the scope of an entailment-cancelling operator.

However, there are cases where presuppositions do not project. In such a scenario the speaker does not presuppose the lexical content of a presupposition, and consequently, listeners do not necessarily understand that Kati used to smoke. Presuppositions can be prevented from appearing by denying them explicitly, when they are embedded under negation, a process that is henceforth called presupposition cancellation. Illustrated in (16), the speaker not only denies that Kati stopped smoking, but also denies that she ever used to.

\section{Simon: Kati didn't stop smoking - she never started in the first place.}

In contrast, embedded under conditionals or questions, presuppositions may be prevented to arise by contextual information, a case that is henceforth called presupposition suspension (Simons, 2001; Abusch, 2010; Abrusán, 2016). Suspension may be enabled by explicit ignorance contexts where listeners know that the speaker is ignorant of the presupposition (Simons, 2001). In example (17), taken from Geurts (1995), the presupposition may be suspended in a context where Simon just met Kati for the first time and does not know anything about her past smoking habits.

\section{Simon: I notice you are chewing on your pencil. Have you recently stopped smoking?}

Whereas all presuppositions may be subject to cancellation, the ease with which they can be suspended was found to vary, which similarly means that projection behaviour varies between presuppositions and their lexical contents. One way of conceptualising projection variability is the gradient property projectivity, i.e. the probability of presuppositions or lexical contents to project. ${ }^{2}$ Projectivity captures the extent to which listeners' are certain that the speaker presupposes content. Thus, although the speaker makes a binary decision to either presuppose content or not, listeners have to infer the speaker's intended meaning under uncertainty. Crucially, projectivity of presuppositions was found to depend on the extent to which presuppositions render their lexical content accessible for contextual influences, manifested by context-dependence of presuppositions. The following section will introduce possible differences in projectivity between presuppositions based on their context-dependence.

\footnotetext{
${ }^{2}$ Projectivity may be applied to the level of presuppositions or to the level of lexical contents, either illustrating differences between presuppositions or differences between lexical contents of the same abstract presupposition.
} 


\subsection{Projectivity of Presuppositions}

Projectivity of presuppositions was claimed to depend on the extent to which contextual factors can affect presuppositions. Unfortunately, determining context-dependence is intricate mainly because it is unclear which of their properties make presuppositions context-dependent or -independent. Taking the relation between presupposition and assertion as starting point, Zeevat (1992) proposed that if a trigger backgrounds its presupposition strongly, the presupposition is less easily addressable, and consequently, less context-dependent. Zeevat (1992) distinguishes between lexical presupposition triggers such as factives and change of state verbs, and resolution triggers such as iteratives. Whereas presuppositions that are associated with lexical triggers are characterised as being context-dependent and less projective, presuppositions associated with resolution triggers are claimed to be context-independent and highly projective. According to Zeevat (1992), this has to do with the way presuppositions and assertions are related: presuppositions of lexical triggers are preconditions for the assertion, since both are logically connected. In (18), Sebastian only could have stopped playing football if he used to play football.

(18) Did Sebastian stop playing football?

Presupposition: Sebastian used to play football.

In contrast, the presupposition of resolution triggers seems logically disconnected to the assertion. In (19), denying the presupposition does not necessarily lead to the falsification of the assertion. Whether Beth may or may not have lost her wallet before, does not change the fact that she lost her wallet today. Hence, iteratives are ought to background their content stronger than change of state verbs, and thereby presuppositions triggered by resolution triggers are less addressable than the content triggered by lexical triggers.

Did Beth lose her wallet again?

Presupposition: Beth lost her wallet before.

But again, this was only one of many approaches that deals with the characterisation of presuppositions. Focusing on the general consent, the majority of approaches agrees that iteratives like again and too may be grouped together as triggering mostly context-independent presuppositions that are highly projective (e.g. Kadmon, 2001; Tonhauser, Beaver, Roberts \& Simons, 2013; Abrusán, 2016). For example, in (20) taken from Simons (2001), the ignorance of the speaker renders the continuation infelicitous, suggesting that at least explicit ignorance contexts may not be sufficient to suspend the presupposition triggered by again.

(20) I have no idea whether Jane ever rented Manhattan, \# but perhaps she is renting it again. 
Zeevat (1992)'s group of lexical presupposition triggers, however, seems to be too coarse-grained. Especially grouping the presupposition triggered by stop together with factives seems to be problematic. Besides being characterised as triggering context-dependent presuppositions (Simons, 2001; Abrusán, 2011), stop has also been described to trigger context-independent presuppositions (Kadmon, 2001; Abrusán, 2016). Already by only focusing on factives - a supposedly homogeneous group of context-dependent presuppositions - it gets apparent that treating context-dependence as binary feature escapes intuitive judgements and findings. For instance, emotive factives (e.g. regret) have been described to be less context-dependent than cognitive factives (e.g. discover). Karttunen (1971) noted that the emotive factive regret and the cognitive factive realise in (21) seem to deviate from the cognitive factive discover. Whereas the presupposition that the addressee had not told the truth in (21) projects more persistently for regret and realise, the presupposition can be suspended more easily for discover. By using discover, the speaker could also simply ask for the facts without necessarily presupposing that the addressee did not tell the truth.

(21) Did you regret/realise/discover that you had not told the truth?

Contrasting these findings with stop in (17), the presupposition seems to be less context-dependent than the one of factives, see example (22), taken from Abrusán (2016). In (22a), one can get a reading where John is not cheating, which is less straightforward in (22b) where a non-presuppositional reading seems odd. However, these claims have to be evaluated with care. For instance, by inserting know or regret in (22a) instead of discover/ realise one gets a similar feeling of oddity that was found for stop in $(22 \mathrm{~b})$. Therefore, it still remains to be resolved where to assemble stop on a continuum of context-dependence.

(22) a. I don't know if John has ever cheated on his wife. But if his wife discovers/realises that he has, he will be in in trouble.

b. ??? I don't know if John has ever cheated on his wife, but if he stopped cheating, then he can take part in our psychological study.

Projectivity of presuppositions seems to depend on the extent to which they are context-dependent. However, in what way can context actually influence projection? The upcoming part of this thesis will introduce contextual factors that have been claimed to influence projection and those linguistic approaches that aimed to formalise and predict presupposition projection based on these factors. Subsequent sections will elaborate on possible differences between presuppositions, and possible differences between lexical contents. 


\section{Chapter 2}

\section{Predicting Projection}

Presupposition projection has been one of the open issues at the semantics-pragmatics interface. In what follows, some accounts that revolve around this debate will be introduced, particularly, those that discuss possible influence factors on projection such as the presence and absence of a local context, discourse structure, presupposition trigger type, and world knowledge. As will be introduced in section 2.1, Heim (1983) proposed that local contexts, such as explicit denial or ignorance contexts, can prevent projection from taking place. In such a case, presuppositions would be only temporarily accepted by listeners and do not enter their common ground for good. However, what happens if the lexical content of a presupposition is rendered to be under debate by the preceding discourse, or if the lexical content of a presupposition is unlikely and/or wonky? Crucially, Heim (1983) can only explain the effect of local contexts on presupposition projection and cannot explain the effects of discourse structure and world knowledge. The possible influence of discourse structure that goes beyond local contexts will be introduced in section 2.2, along with pragmatic approaches such as Simons, Tonhauser, Beaver and Roberts (2010, 2016). Besides being faced with their specific drawbacks, the theories that have been mentioned so far share the same problem of over-generalisation, i.e. they have difficulties explaining projection variability between presuppositions. Therefore, Abrusán (2011, 2016)'s account will be presented subsequently in section 2.3, which makes predictions about differences between presuppositions. Moreover, this approach suggests that there are further factors beyond discourse structure, that may influence projection such as world knowledge. For example, when listeners hear an utterance such as 'Alex discovered that Sebastian flew to Moscow/to the moon.', would they less likely understand that Sebastian indeed flew to the moon than to Moscow, since flying to the moon is far less likely than flying to Moscow? Crucially, whereas the factors local context, discourse structure and presupposition trigger type operate on the presuppositional level, world knowledge could explain differences in projectivity between lexical contents. The possible influence of world knowledge in form of prior probabilities 
of events will be introduced in section 2.4, along with the Rational Speech Act framework (Franke \& Jäger, 2016; Goodman \& Frank, 2016). The idea that prior probabilities of events enter the interpretation process of listeners originates in this framework and discussing research within this framework illustrates best, to what extent world knowledge may influence listeners' interpretations. All theories will be discussed by extracting their specific predictions on projection and contrast those with empirical findings.

\section{$2.1 \quad$ Local Contexts}

\subsubsection{Global and local accommodation}

The purpose of the following section is to outline an example of formalising and predicting the effects of local contexts on the processing of presuppositions, such as explicit denial or ignorance contexts. To understand how local contexts interfere with presuppositions, consider that presuppositions are commonly claimed to impose requirements on the context, such that they must be entailed by, or satisfied in, the common ground of the interlocutors (e.g. Stalnaker, 1974; Karttunen, 1974). Here, 'context' refers to the overall context of utterances against which they are evaluated. Formally, a context of an utterance may be understood as a set of possible worlds. In fact, the context set contains all possible worlds that are compatible with information in the common ground. Recall that the common ground constitutes a set of propositions ${ }^{1}$ that are considered as true between interlocutors. Making assertions means to add new propositions to the common ground, and to discard all those worlds from the context set that are not compatible with the added propositions. Understanding presuppositions as requirements on the context leads in two cases to presupposition failure. First, when the presupposition conveys new information and is therefore not already entailed by the common ground, and second, when local contexts introduce information contradicting the content conveyed by the presupposition.

Heim (1983) assumes two strategies that listeners can pursue when they are confronted with new presuppositions in entailment-cancelling environments: global and local accommodation. In her theory of context change semantics, the semantics defines context change potentials (CCPs) — which are functions from contexts to contexts - for expressions. Informally, CCPs specify operations that have to be applied to contexts. For example, the CCP of 'Sebastian moved to Berlin' instructs to intersect the current context $\mathrm{C}$ with the set of worlds where Sebastian moved to Berlin. The result of applying the $\mathrm{CCP}$ of a sentence $\mathrm{S}^{2}$ to a context $\mathrm{C}$ will be written as $C+S$, and since presuppositions are understood to be requirements on contexts, $C+S$ is only defined for those

\footnotetext{
${ }^{1} \mathrm{~A}$ proposition $\mathrm{p}$ of a sentence $\mathrm{S}$ is defined as a set of possible worlds in which $\mathrm{S}$ is true.

${ }^{2}$ For simplicity, it will be assumed that simple sentences $\mathrm{S}$ are closed atomic formulas and for each $\mathrm{S}$ the sets of worlds in which $\mathrm{S}$ is true (i.e. the propositions of $\mathrm{S}$ ) are given.
} 
contexts that entail $\operatorname{psp}(\mathrm{S})$, where $\operatorname{psp}(\mathrm{S})$ means 'the presupposition of $\mathrm{S}$ ':

(23) If $\mathrm{C}$ entails $\operatorname{psp}(\mathrm{S})$, the $\mathrm{CCP}$ for any $\mathrm{S}$ is defined as the set of worlds that $\mathrm{C}$ and $\mathrm{S}$ have in common $(C \cap\{\mathrm{w}: \mathrm{S}$ is true in w $\})$. If $\mathrm{C}$ does not entail $\mathrm{psp}(\mathrm{S})$, the $\mathrm{CCP}$ for $\mathrm{S}$ is undefined.

For example, (24) can only be added to those contexts $\mathrm{C}$ entailing that David used to work as a ballet dancer. If a context $\mathrm{C}$ entails $\operatorname{psp}(24), C+(24)$ is computed by intersecting $\mathrm{C}$ with the set of worlds in which David stopped working as a ballet dancer. The result is a context containing only those worlds where David used to work as a ballet dancer but does not do so any more.

(24) David stopped working as a ballet dancer.

(25) David didn't stop working as a ballet dancer.

In what way can Heim (1983) explain presupposition projection? Taking negation as an example, it needs to be explained why $\operatorname{psp}(\mathrm{S})$ must also be entailed by $\mathrm{C}$ for $\neg S$. This is achieved by formulating the $\mathrm{CCP}$ of negation as operation that subtracts from $\mathrm{C}$ the set of worlds where $\mathrm{S}$ is true:

$$
C+\neg S=C-(C+S)
$$

Crucially, in this way the CCP of $\neg S$ is only defined if C entails $\operatorname{psp}(\mathrm{S})$, since we need $C+S$ to calculate $C+(\neg S)$. Thus, $(25)$ is calculated by subtracting from $\mathrm{C}$ all the worlds where David stopped working as a ballet dancer, see (27).

$$
C+(25)=C-(C+(24))
$$

As was specified by (23), the CCP of $\mathrm{S}$ is undefined if $\mathrm{C}$ does not entail $\operatorname{psp}(\mathrm{S})$. This would mean that cases where the presupposition introduces new content, and thus, C does not entail psp $(\mathrm{S})$ would lead to presupposition failure and the conversation would collapse. Again, such a scenario is not realistic, so that Heim (1983) resorts to presupposition accommodation to prevent presupposition failure. There are two cases of presupposition failure: (i) when $\mathrm{S}$ is uttered in a context where $\operatorname{psp}(\mathrm{S})$ is unknown, (ii) when $\mathrm{S}$ is uttered in contexts that hint to the fact that $\operatorname{psp}(\mathrm{S})$ contradicts C (e.g. as in explicit denial or ignorance contexts). In the first case, global accommodation is performed. This basically means that instead of using the initial context $\mathrm{C}$, listeners are taken to alter it by adding the presupposition to C, i.e. $C \rightarrow C \& p s p(S)$. Global accommodation for (25) proceeds in the following steps:

1. Initial $\mathrm{C}$ is altered to $\mathrm{C} \& \operatorname{psp}(24)$

2. Calculate: $C+\neg(24)=C \& p s p(24)-(C \& p s p(24)+(24))$ 
Thus, the amended context $\mathrm{C} \& \operatorname{psp}(\mathrm{S})$ is used instead of $\mathrm{C}$, leading to the same calculation as in (27): the set of worlds where David used to work as a ballet dancer and where he stopped doing so is intersected with the set of worlds where David used to work as a ballet dancer. The result is a new context containing only those worlds where David used to work as a ballet dancer and did not stop doing so. Hence, $\operatorname{psp}(\mathrm{S})$ entered the common ground for good, a case where presuppositions project.

When the context is not necessarily compatible with the presupposition that David used to work as a ballet dancer, for example when the presupposition contradicts the context in explicit denial contexts, see (28), the presupposition is accommodated locally.

(28) David didn't stop working as a ballet dancer - he never used to!/he only recently started!

Local accommodation proceeds as follows:

1. Initial $\mathrm{C}$ is changed to $\mathrm{C} \& \operatorname{psp}(24)$ only for the purpose of computing $(C+(24))$

2. Calculate: $C+\neg(24)=C-(C \& p s p(24)+(24))$

Here, those worlds of contexts where David used to work as ballet dancer and stopped doing so is intersected with the set of worlds where he either used to work as a ballet dancer or he did not, such that only those worlds of contexts remain in which David either did not used to work as a ballet dancer or he did so but he did not stop. Hence, $\operatorname{psp}(\mathrm{S})$ does not enter the common ground for good, but instead is only used on a local level for the purpose of computing the CCP of $\neg S$. Similarly, one may say that listeners who accommodate locally get a non-presupposition reading, as case where presupposition projection was prevented.

According to Heim (1983), local accommodation must be licensed by current context information, e.g. by an explicit denial of the presupposition. In a case where $\operatorname{psp}(\mathrm{S})$ is new information, and there is no evidence that contradicts $\operatorname{psp}(\mathrm{S})$, listeners accommodate presuppositions globally which means that those presuppositions project. Consequently, when utterances containing presupposition triggers are processed in isolation, global accommodation is the default and preferred over local accommodation. However, there are examples where one might argue against such a preference.

(29) If Sue stopped smoking yesterday, for example, that would explain why she is nervous today.

(30) If Sue stopped smoking yesterday, we can throw out the ashtrays.

For instance, Kadmon (2001, p. 172 f.) argues that local accommodation is not only performed when global accommodation is not possible. She claims that for (29) one can easily get a local reading, opposed to (29) where it is strongly suggested that Sue used to smoke. Since both examples are presented in isolation - there is no context that can license local accommodation-local 
accommodation should not be possible which, contrary to the claim, takes place after all. Evidently, cases where presuppositions have been claimed to project by all means, do not do so.

\section{Predictions}

- Heim (1983): When there is no context that could license local accommodation, global accommodation takes place. Thus, the presupposition projects.

\subsubsection{Global versus local accommodation}

When speakers willingly or unwillingly introduce new information by presupposing it, listeners are said to accommodate the presupposition. In embedding environments, listeners can resort back to either global or local accommodation, whereby the former was claimed to be preferred over the latter according to Heim (1983). However, some examples hint to the fact that local accommodation is not exclusively performed when global accommodation is not possible, e.g. when the presupposition contradicts a given context. The following section will present empirical findings on whether global accommodation is preferred over local accommodation, and whether the latter case is only performed by listeners when there is a local context that licenses local accommodation.

Chemla and Bott (2013) investigated whether global accommodation is preferred over local accommodation for the factive verb realise under negation by using a truth judgement task. The authors based their examination on the assumption that default processes are quicker than backup processes, leading to the prediction that global accommodation is a faster process than local accommodation. Participants had to judge whether sentences containing discover are true or false, whereby these sentences either conveyed true or false presuppositions. Judging sentences with false presuppositions, e.g. (31b), as being true was taken to correspond to local accommodation, since the presupposition was only temporarily accepted for the sake of rendering the sentence true as a whole. Since the content of a false presupposition was evidently false, it was not assumed that participants added such false information to their common ground for good.

a. Zoologists don't realise that elephants are mammals.

b. Zoologists don't realise that elephants are reptiles.

Participants gave 'true' and 'false' responses when they read sentences such as (31b) but the 'false' responses were found to be significantly faster than the 'true' responses. These findings were taken as evidence for the claim that global accommodation is the default process. However, this equally illustrates that there have been cases where local accommodation was applied, although there was no local context that could have licensed this process. 
Romoli and Schwarz (2015)'s study on stop under negation supports these findings. They conducted a picture selection task within the 'covered box' paradigm. Participants had to select one out of three pictures - one of which was covered - that they thought corresponded best to a given sentence's interpretation. According to the covered box paradigm, participants are assumed to chose the covered box when they do not find a suitable match between presented pictures and the stimulus. Their findings illustrated that local interpretations were accepted significantly less often by participants than global ones, since the covered picture was chosen significantly more often when there was only a picture depicting a local interpretation as alternative. Furthermore, participants needed significantly more time for their picture choices when they had to decide between a picture that corresponded to a local/non-presuppositional interpretation and a covered picture. Consequently, the authors conclude that global accommodation is the default process as was suggested by Heim (1983). However, similar to the findings on the factive realise (Chemla \& Bott, 2013), the presupposition triggered by stop was found to be accommodated locally, despite being processed in isolation.

Studies that examined the ease with which presuppositions can be accommodated locally are often related to the presupposition triggers' typology. For example as was introduced in section 1.3, Zeevat (1992) distinguishes between lexical presupposition triggers such as factives and change of state verbs and resolution triggers such as iteratives. Zeevat (1992) argued that presuppositions that are strongly backgrounded are less context-dependent and associated with a high projectivity. In other words, the extent to which presuppositions are backgrounded may influence the ease with which listeners can accommodate presuppositions locally. Presuppositions that are strongly backgrounded should be less easy to accommodate locally. Cummins, Amaral and Katsos (2013) investigated this division between triggers in terms of backgrounding effects empirically, by letting participants rate the acceptability of continuations that either falsified or verified the assertion or the presupposition. See (32) for experimental items with quit. $^{3}$

(32) Did Kati quit smoking?

a. Yes, she quit smoking. (addressing assertion, global accommodation)

b. Yes, although she never used to smoke. (addressing presupposition, psp cancellation)

c. No, she didn't quit smoking. (addressing assertion, global accommodation)

d. No, because she never used to smoke. (addressing presupposition, local accommodation)

Continuations where the presupposition was not addressed were taken to correspond to global accommodation (32a) and (32c). In contrast, local accommodation was assumed to take place for (32d), where the assertion was denied by 'No', and the presupposition was falsified in the continuation. Their findings illustrate that global accommodation of presupposition was preferred over

\footnotetext{
${ }^{3}$ It will be assumed that there is no semantic difference between quit and stop.
} 
local accommodation: continuations where the presupposition was not suspended, as in (32a)/ (32c), were rated significantly higher than continuations where the presupposition had to be accommodated locally, as in (32d). Furthermore, they found a distinction between iteratives and lexical triggers like factives and change of state verbs when it comes to the relation between assertion and presupposition: For lexical triggers, participants found continuations that falsified the presupposition significantly more acceptable when the assertion was denied, as in (32d), than when presupposition was falsified but the assertion approved, as in (32c). This was different for iteratives where no significant difference between these conditions was found. This is in accordance with Zeevat (1992)'s suggestion that assertion and presupposition for resolution triggers are not logically connected, making it acceptable to deny the presupposition and to accept the assertion. ${ }^{4}$

It became evident, that global accommodation of presuppositions seems to be a quicker and more frequently applied process than local accommodation. Nevertheless, local accommodation was performed for utterances in isolation, suggesting that local contexts may not the only factor that can license local accommodation. Additionally, Cummins et al. (2013)'s findings suggest that projectivity varies between presuppositions which is a further factor that Heim (1983)'s account cannot explain. Hence, it becomes more and more evident that presupposition projection can only be partially captured by a distinction between content that projects and content that does not project.

\subsection{Discourse Structure}

\subsubsection{At-issueness and the QUD}

Evidently, listeners use discourse structure and contextual information when they interpret utterances. For example, conversational implicatures only arise in specific contexts and not in others. Although presuppositions are far less context-dependent, contextual factors have been found to influence projection. The influence of discourse structure on presupposition projection is related to their unique discourse status as being backgrounded beliefs of the speaker (Stalnaker, 1974). More specifically, presuppositions have been established to be already known information and taken for granted (Chierchia \& McConnell-Ginet, 2000), and are thus not part of the main point (Abbott, 2000), and not at-issue (Potts, 2005). The discourse status of presuppositions contrasts with newly introduced information that is most often said to be focused. Focus in the sense of Jackendoff (1972), is a theoretical notion that describes the relation between prosodic prominence - most often realised by a nuclear pitch accent - and pragmatic/semantic effects. Pragmatically, focused material generally addresses the explicit or implicit Question under Discussion (QUD). In the sense of Roberts (1996), the QUD corresponds to the current discourse topic.

\footnotetext{
${ }^{4}$ Considering 'Did Beth lose her wallet again?', whether Beth lost or did not lose her wallet today is independent of her having lost her wallet before. See section 1.3 for more details.
} 
a. Lydia went to the ZOO.

b. LYDIA went to the zoo.

Taking (33) as an example, where capital letters signal narrowly focused constituents, (33a) is commonly understood to address an implicit QUD such as Where did Lydia go to?, and (33b) addresses a question such as Who went to the zoo? The focused content is, by addressing the QUD, not already established information, but instead, at-issue content that is up for debate. Apparently, this contrasts with the discourse status of presuppositions, leading to the question of whether the discourse status of presuppositions may be altered throughout the discourse, and in what way this alteration influences projection.

In fact, the lexical content of presuppositions can be made at-issue via prosodic cues which in turn, influences whether that content projects or not. For illustration on factives, consider (34), taken from Beaver (2010, p. 93), where focused expressions are enclosed in brackets and subscribed with ' $\mathrm{F}$ '. Beaver (2010) claimed that as long as the factive predicate is accented and its complement is de-accented, such as in (34b), it is implied that the student is guilty, and thus, the presupposition projects. This changes for $(34 \mathrm{a})$ where the constituent of the embedded clause, and thereby, the content of the complement is narrowly focused. Here, the presupposition did not necessarily project.

(34) a. If the TA discovers that [your work is plagiarized $]_{F}$, I will be [forced to notify the Dean $]_{F}$.

b. If the TA [discovers $]_{F}$ that your work is plagiarized, I will be [forced to notify the Dean $]_{F}$.

Simons et al. (2010) expanded Beaver (2010)'s findings on factives by proposing an approach on projective meaning - covering not only presuppositions but all implications that survive entailmentcancelling embeddings. This includes conventionally triggered implicatures like non-restrictive relative clauses which ought to project but are not presupposed (Potts, 2005). Simons et al. (2010) argued that embedded implications potentially project as long as they are not-at-issue relative to the discourse topic, i.e. the QUD, based on the assumption that only at-issue content is targeted by entailment-cancelling operators. Further, linguistic content is at-issue as long as it is relevant to the QUD, which is only the case iff it entails a partial or complete answer to the QUD.

Background scenario: a nutritionist has been visiting first grade classrooms to talk to children about healthy eating

Q: What most surprised you about the first graders?

A: They didn't know that you can eat raw vegetables.

For illustration, consider (35), taken from Simons et al. (2010, p. 317), where the QUD is explicitly stated: What most surprised you about the first graders?. There are two implications embedded under negation: (a) the proposition You can eat raw vegetables and (b) They knew that you can eat 
raw vegetables. Simons et al. (2010) argue that (a) projects, since it is not relevant to the QUD. In contrast, (b) does not project because it addresses the QUD and is consequently at-issue.

(36) I notice you are chewing on your pencil. Have you recently stopped smoking?

Similarly, for stop in (36) there are two implications that are embedded under the polar question operator: (a) You have recently stopped smoking, and (b) You used to smoke. Taking the preceding sentence into account, one may construe an implicit QUD such as What is the reason for your nervousness?. Hence, the fact that the person in (36) used to smoke is at-issue relative to the QUD, since it would explain her or his nervousness. Consequently, (b) is predicted not to project.

The problem that such an account faces is that it overestimates context-sensitivity of presuppositions, and thereby, the ease with which lexical content of presuppositions can become at-issue and suspended. For example, Abrusán (2011) pointed out that Simons et al. (2010)'s account would falsely predict that the implication the first graders indeed failed the exam in (37) does not project. This is because in a context where the exam was very easy, the implication can be understood to be relevant to the QUD and thereby should be at-issue. But this seems to go against our intuitions.

Background scenario: The exam for the first graders was very easy.

Q: What most surprised you about the first graders?

A: They didn't know that they have failed the exam.

Their problem of over-estimation partly results from treating all presuppositions equally. This is why pragmatic accounts, e.g. Simons et al. (2016), often focus on factives that are commonly claimed to be conversationally derived. Moreover, Simons et al. (2016) may account for cases where content projects, despite being at-issue. They base their theory on two hypotheses:

1. content that projects is either not-at-issue because it is entailed by the congruent question, or

2. it is not-at-issue because it is required to be not-at-issue in order to render the congruent question relevant to the overall discourse question (QUD)

First, the congruent question is defined as the focal alternative set of an utterance. For example in (38b), the congruent question is Who knows that Sebastian likes hummus?, which opens up the focal alternative set of propositions $\{p$ : for some entity a, a knows that Sebastian likes hummus $\}$ where $a$ may be any person that was made salient in the context, one of which is Alex.

a. Perhaps Alex $[\text { knows }]_{F}$ that Sebastian likes hummus?

Does Alex believe/know that Sebastian likes hummus?

$\{p$ : for some relation $R$, Alex $R$ that Sebastian likes hummus $\}$ 
b. Perhaps $[\text { Alex }]_{F}$ knows that Sebastian likes hummus?

Who knows that Sebastian likes hummus?

$\{p$ : for some entity a, a knows that Sebastian likes hummus\}

c. Perhaps Alex knows that [Sebastian $]_{F}$ likes hummus?

Who does Alex know likes hummus?

$\{p$ : for some entity a, Alex knows that a likes hummus\}

d. Perhaps Alex knows that Sebastian [likes hummus] $]_{F}$ ?

What does Alex know about Sebastian?

$\{p$ : for some property $P$, Alex knows that Sebastian P $\}$

According to Simons et al. (2016) the content that Sebastian likes hummus projects only in (38a) and $(38 \mathrm{~b})$, but not in the two latter cases (38c-38d). In (38c), the content that someone but not necessarily Sebastian likes hummus projects, and in (38c) the content that some property for Sebastian is true projects, but not necessarily that he likes hummus. Hence, content that stays the same across focal alternatives is the one that projects, i.e. the congruent question has to entail the content so that it can project.

The advantage of Simons et al. (2016)'s account over the one of Simons et al. (2010) is accomplished by introducing the notion of discourse coherence. Content that does not project is either not-atissue with respect to the congruent question (is not entailed by all focal alternatives) or not-at-issue with respect to the QUD. The latter means that the content remains not at-issue since it has to be invariant across alternatives to render the congruent question of an utterance conversationally coherent.

(39) Background scenario: The exam for the first graders was very easy.

Q: What most surprised you about the first graders?

A: They didn't know that they have [failed the exam $]_{F}$.

$\{p$ : for some property $P$, the didn't know that they have $P\}$

Hence, Simons et al. (2016) would account for Abrusán (2011)'s counter-example in claiming that a non-presuppositional reading of (39), where the first graders had not failed the exam, would not be relevant to the QUD (What most surprised you about the first graders?). Therefore, the content is predicted to project although it is at-issue.

Although having offered a refined analysis, Simons et al. (2016) are only able to formulate predictions for presuppositions triggered by factives, and moreover, they make no predictions about differences between factives. Furthermore, similar to Heim (1983)'s account, they only make a categorical distinction between content that is at-issue and does not project and content that is not-at-issue and does project. However, this section illustrated the influence of at-issueness on projection. 
In contrast, conventional approaches cannot explain why narrow focus on a constituent can lead to projection suspension when there is no contextual information available that may license local accommodation. In the next section, findings on the influence of at-issueness on projection will be presented.

\section{Predictions}

1. Simons et al. (2010): All and only those implications of (embedded) sentences which are not-at-issue relative to the Question Under Discussion in the context have the potential to project.

No difference between projective contents.

2. Simons et al. (2016): The lexical content of presuppositions triggered by factives projects if (i) it is either not-at-issue because it is entailed by the congruent question, or (ii) it is not-at-issue because it is required to be not-at-issue in order to render the congruent question relevant to the overall discourse question (QUD)

No difference between factives, and no predictions on stop

\subsubsection{Investigating at-issueness}

The hypothesis that presuppositions projection is sensitive to the QUD indicated by prosodic cues was firstly investigated by Cummins and Rohde (2015). They examined 20 different presupposition triggers embedded under negation, among others the change of state verb stop, emotive factive verbs, cognitive factives, and the iterative again. The sentences were presented in two different conditions: a prosody neutral condition, see (40a), and a focus condition where a pitch accent was placed on the last word of the sentence, see (40b). Note that prosody was not systematically manipulated. Moreover, it is not clear how 'neutral' prosody was achieved.

(40) a. Bill doesn't regret arguing with his boss.

b. Bill doesn't regret arguing with his BOSS.

c. How likely does Bill argue with his boss?

Sentences of the neutral condition, such as (40a) with a stress placed on doesn't were taken to answer a QUD like Does Bill regret arguing with his boss?. Following Simons et al. (2016)'s reasoning, (40a) would be a case where the presupposition projects, since all alternatives that are evoked by such a 
question entail the presupposition that Bill argued with his boss. In contrast, (40b) is a case where the presupposition is less likely to project. The focal stress on boss corresponds to a QUD such as With whom doesn't Bill regret arguing with?, evoking a different set of alternatives, where Bill regret arguing with someone, but not necessarily his boss.

Seventy-seven participants were recruited over Amazon Mechanical Turk and each participant was exposed to all twenty items, half in the neutral and half in the focus condition. Participants had to rate how likely they think the lexical content of a presupposition was, see (40c). Ratings were given on a 7-point Likert scale, where 1 was labelled 'unlikely' and 7 'likely'. Cummins and Rohde (2015)'s findings suggest that listeners are indeed sensitive to the QUD and consider prosodic cues when they interpret presuppositions: Participants rated presuppositions to be less likely in the focus condition than in the neutral condition. Thus, when content was prosodically marked as being at-issue relative to a QUD, the projectivity of that content was reduced. Crucially, the effect strengths of prosodyand consequently at-issueness - varied across presupposition triggers. Cognitive factives (know, be aware were found to be more affected by prosodic cues than emotives (regret, be happy, be sorry), which in turn were more affected than the iterative again. Moreover, for stop prosody had the opposite effect. Participants rated presuppositions triggered by stop in the focus condition to be more likely than in the neutral condition - the same goes for return, manage and forget. Taking a closer look at (41), this means that participants found the lexical content Rachel used to smoke cigarettes more likely in (41b) than in (41a), opposed to the claims that where made by Simons et al. (2010).
a. Rachel didn't stop smoking cigarettes.
b. Rachel didn't stop smoking CIGARETTES.

However, these findings have to be evaluated with care, mainly because (i) prosody was not systematically manipulated, and (ii) focus placement was scarcely motivated. Firstly, it is unclear in what way experimental items in the neutral condition were realised, making a comparison between conditions difficult. Secondly, the focus on cigarettes was only motivated by the general stipulation to stress the last word of each experimental item. In order to make the strong claim that presuppositions of stop are not sensitive to prosodic cues, one would have to investigate alternative focus placements, such as in (42).

(42) RACHEL didn’t stop smoking cigarettes.

However, Cummins and Rohde (2015)'s findings suggest that the effect strength of prosodic cues, and in similar vein, at-issueness on projectivity differs between presupposition triggers - even within the group of factives - for which Simons et al. (2010, 2016) cannot account for.

Cummins and Rohde (2015)'s study was refined by Tonhauser (2016) who manipulated prosody 


\begin{tabular}{lll} 
Condition & Stimuli & Prosody \\
\hline a & Perhaps he discoVERed that she's a widow & $\mathrm{H}^{*}$-on-predicate \\
b & Perhaps he discovered that she's a WIdow & L $+\mathrm{H}^{*}$-on-last word \\
c & Perhaps he discovered that shE's a widow & L $+\mathrm{H}^{*}$-on-pronoun
\end{tabular}

Table 2.1: Experimental stimuli

systematically. Their findings will be presented briefly, since (i) it supports the findings of Cummins and Rohde (2015) on projection variability between factives, and (ii) demonstrates the effect of slight prosodic variations on projectivity. As is illustrated in table 2.1 where capitals mark the greatest prosodic prominence of the sentence, three conditions were investigated. In condition (a) the predicate was emphasised by a high tone pitch accent. In the two remaining conditions $(\mathrm{b}-\mathrm{c})$, constituents of the complement were emphasised with a complex pitch accent on either the last word (b) or the pronoun (c). Data assessment was similar to Cummins and Rohde (2015). Participants had to answer the question Is the speaker certain that $X$ where $\mathrm{X}$ denotes the lexical content of a presupposition, e.g. for the experimental items in 2.1, the question was Is the speaker certain that she is a widow? Participants assessed speaker certainty by rating the stimuli on a 7-point Likert-scale where 1 was labelled 'No, not certain' and 7 was labelled 'Yes, certain'. A 'Yes, certain' rating was taken to mean that the lexical content of the presupposition projected.

Tonhauser (2016)'s findings suggest that projectivity of presuppositions that are triggered by factives is influenced by prosodic cues that may render their lexical content at issue. If an expression of the complement was narrowly focused and prosodic cues hinted to the fact that this content was at-issue, as in conditions (b) and (c), it less likely projected than in condition (a) where the content of the complement was de-accented and not marked at-issue. On an additional note, Tonhauser (2016) found evidence that not only the place of the pitch accent, but also the type of pitch accent plays a role in affecting projectivity. In a further experiment, sentences with different types of pitch accents on the predicate and last content word were compared. They found that when the pitch accent on the last word was less prominent than the pitch accent on the predicate, lexical content was more likely to project than when the pitch accent on the last word was more prominent than the one on the predicate. All in all, Tonhauser (2016), confirmed Simons et al. (2016)'s claim about the influence of at-issueness on projectivity, but illustrated that there are differences between triggers for which a theory that wants to predict presupposition projection should account for. In the following sections, a third account will be introduced which may be assembled between the two preceding ones. Crucially, this approach makes detailed predictions on presupposition projection and possible differences between triggers. 


\subsection{Attention and variability}

\subsubsection{The default main point}

One account that considers grammatical constraints and contextual information to capture projection variability, is the one formulated in Abrusán (2011) and further developed in Abrusán (2016). According to this approach, attention structures information, such that listeners pay attention to some aspects of meaning by default, and contextual cues can direct their attention to further aspects. More specifically, attention is a process that unfolds in two steps, (i) the default main point is determined by grammatical constraints (bottom-up), and (ii) the pragmatic secondary main point is introduced by contextual cues (top-down). Projection is explained in terms of listeners' attention: everything that listeners do not pay attention to is not part of the main point and presupposed. Abrusán (2011) defines the default triggering mechanism as a function that takes the meaning of a sentence $\mathrm{S}$ and a context $\mathrm{C}$, and outputs a non-exhaustive list of entailments of $\mathrm{S}$. On the conversational level, the list of entailments is understood to be made intuitively by listeners. Example (43) taken from (Abrusán, 2011, p. 18) illustrates a possible list of entailments for the factive verb know:

$\mathrm{S}=$ John knows $\left(\right.$ at $\left.t_{1}\right)$ that it was raining $\left(\right.$ at $\left.t_{2}\right)$.

a. John knows (at $\left.t_{1}\right)$ that it is raining (at $\left.t_{2}\right)$

b. John believes (at $t_{1}$ ) that it is raining (at $t_{2}$ )

c. It is raining (at $\left.t_{2}\right)$

d. It is humid (at $\left.t_{2}\right)$

Those entailments of $\mathrm{S}$ that are about the event time of the matrix predicate constitute the main point. Event times are time intervals that receive their value from the context. Entailments that are not about the event time of the matrix predicate are presupposed. Thus, presuppositions are defined as being part of the entailed meaning. ${ }^{5}$ Consequently, the difference between the presupposition trigger know and the common verb believe gets already apparent at this point: Whereas know entails the truth of its complement (43c), believe does not.

To assess whether an entailment of $\mathrm{S}$ is indeed presupposed, one has to determine whether that entailment is about the event time of the matrix predicate of S. In (43), matrix tense and embedded tense did not receive the same denotations from the context, and assuming that $t_{1}$ and $t_{2}$ do not overlap, only entailments (43a) and (43b) are about $t_{1}$ : changing properties of the world at $t_{1}-$ e.g. that John did not know that X-will influence the truth of (43a-43b). In contrast, (43c) and (43d)

\footnotetext{
${ }^{5}$ Nonetheless, Abrusán (2011) defines presupposition to be 'somewhat different from usual entailments'. See example 12 for illustrative purposes on the distinction between entailments and presuppositions.
} 
are not about $t_{1}$ : changing properties of the world at $t_{1}$ will not change the truth of these two entailments, and thus, they are predicted to be presupposed.

$\mathrm{S}=$ John knows $\left(\right.$ at $\left.t_{1}\right)$ that it was raining (at $\left.t_{1}\right)$.

a. John knows (at $\left.t_{1}\right)$ that it is raining (at $\left.t_{1}\right)$

b. John believes (at $\left.t_{1}\right)$ that it is raining (at $\left.t_{1}\right)$

c. It is raining (at $\left.t_{1}\right)$

d. It is humid (at $\left.t_{1}\right)$

This simple mechanism would over-predict presupposition suspension. Namely, always when embedded tense and matrix tense received the same denotations from the context, as in (44). Here, changing the properties of the world at $t_{1}$ changes the truth of the entailments $(44 \mathrm{c}-44 \mathrm{~d})$ and these two entailments are not presupposed. This is why Abrusán (2011) distinguishes between accidental and non accidental co-temporaneity (Abrusán, 2011, p. 17):

Take an entailment $\mathrm{p}$ of $\mathrm{S}$. If there is a well formed alternative $\mathrm{S}$ ' to $\mathrm{S}$ such that the corresponding entailment to p (namely p' of S') can be expressed by a sentence that is not about the event time of the matrix clause of S', then I will say that $\mathrm{p}$ is only accidentally about the matrix event time of $\mathrm{S}$.

Back to (44), the entailment it is raining (at $\left.t_{1}\right)$ is only accidentally about $t_{1}$, since there is a well formed alternative to $\mathrm{S}$ which is John knows (at $t_{1}$ ) that it was raining (at $t_{2}$ ) with the corresponding entailment it is raining at $t_{2}$. Hence, entailments (44c) and (44d) are accidentally about the event time of the matrix predicate in (44) and nonetheless end up as being presupposed. In contrast, implicative verbs like manage, lexically specify the tense of their complement to be co-indexed with the matrix tense. This means that (45) has no well formed alternative where embedded and matrix time are different. Thus, the entailment the door is open (at $\left.t_{1}\right)$ will not be presupposed.

(45) John managed (at $\left.t_{1}\right)$ to open the door (at $\left.t_{1}\right)$.

Alternative: *John managed (at $t_{1}$ ) to open the door (at $\left.t_{2}\right)$.

\#John managed to open the door next week.

This kind of analysis may be extended to the whole class of factive verbs including realise, notice, find out, etc. and emotive factive verbs like regret, to be annoyed, to be happy/upset, etc.. The change of state verb stop deviates minimally from this analysis which is also true for the cognitive change of state verb discover. Beginning with stop, see (46) taken from Abrusán (2011, p. 25).

$$
\mathrm{S}=\text { John stopped smoking }\left(\text { at } t_{1}\right) \text {. }
$$


a. John does not smoke (at $\left.t_{1}\right)$

b. John smoked (at $t_{2}$ where $t_{2}$ is some contextually given interval before $t_{1}$ )

c. John stopped smoking (at $\left.t_{1}\right)$

Crucially, the meaning of stop entails that the entailment (46b) proceeds the event time of the matrix predicate. This means that changing the properties of the world at $t_{1}$ does not affect the truth of (46b) in any case. Thus, for stop there are no temporal alternatives. The analysis for cognitive change of state verbs, e.g. discover, is similar to both, factives and change of state verbs, see (47) taken from Abrusán (2011, p. 28):

(47) $\mathrm{S}=$ Peter discovered (at $\left.t_{1}\right)$ that Mary is tired (at $\left.t_{1}\right)$.

a. Peter did not know that Mary is tired at $t_{2}$ (where $\left.t_{2}>t_{1}\right)$

b. Mary is tired at $t_{1}$

Entailment (47a) is presupposed because discover entails that entailment (47a) proceed the matrix tense $t_{1}$, and entailment (47b) is predicted to be presupposed since it is only accidentally about the matrix tense $t_{1}$.

Consequently, the default mechanism predicts that the complement of factives and cognitive change of state verbs is always presupposed, since as long as the event times are independent there will always be a temporal alternative. This may be contrasted with verbs like manage which specify the tense argument of their complement to be co-indexed with the matrix time. And the pre-state entailments of change of state verbs, including cognitive change of state verbs, is always presupposed since it is always about an event time other than the one of the matrix predicate.

\subsubsection{The secondary main point}

Presupposition suspension happens when attention is broadened by contextual cues, such that entailments that would have been presupposed by default, become part of the contextually introduced secondary main point. Thus, presuppositions need to be independent from both, default main point and secondary main point. Focus placement belongs to one of the possible top-down factors that can introduce a secondary main point, and is in fact, the most discussed one. As was already introduced in previous sections, focused information directly answers a background question, and in doing so, it constitutes the secondary main point. For illustration of this process see (48), the already discussed example (34) taken from Beaver (2010), see section 2.2.1.

a. If the TA discovers (at $\left.t_{1}\right)$ that [your work is plagiarised $\left(\right.$ at $\left.\left.t_{2}\right)\right]_{F}$, I will be [forced to notify the Dean $]_{F}$. 
b. If the TA [discovers $]_{F}$ (at $\left.t_{1}\right)$ that your work is plagiarised (at $\left.t_{2}\right)$, I will be [forced to notify the Dean $]_{F}$.

The main point in both $(48 \mathrm{a}-48 \mathrm{~b})$, is about the TA discovering that $\mathrm{X}$ at $t_{1}$, where $\mathrm{X}$ stands for the embedded clause. In (48a), the embedded clause that your work is plagiarised is focused and introduces a secondary main point by addressing the background question What will the TA discover at $t_{1}$ ?. In order for the entailment your work is indeed plagiarised (at $t_{2}$ ) to be presupposed it needs to be independent from the main point and the secondary main point. This time, changing the properties of the world at $t_{1}$ changes the truth of the embedded clause's entailment: The TA discovers that either the work is plagiarised at $t_{1}$, a case where it is indeed plagiarised, or that the work is not plagiarised at $t_{1}$, a case where it is not plagiarised. Hence, the entailment your work is indeed plagiarised ( $a t t_{2}$ ) is not presupposed, since it depends on the secondary main point. This contrasts with (48b) where focus indicates the background question What will the TA do? Here, the secondary main point is the same as the grammatical main point which means that the entailment of the embedded clause is presupposed. Changing the properties of the world at $t_{1}$, does not change the truth of your work is plagiarised at $t_{2}$ : The TA either does discover or does not discover that your work is plagiarised which does not change the fact that it is indeed plagiarised. To sum up, as long as there is no further context information, presuppositions project by default. When there are additional contextual cues, presuppositions may be suspended, if those cues introduce a secondary main point other than the default main point.

In what way does the mechanism explain differences between triggers when it comes to their projection behaviour? Crucially, all presuppositions are triggered by the same underlying mechanism (Abrusán, 2016). Presupposition triggers are claimed to differ from each other in the way they interact with context information. Here, only the factor focus sensitivity will be discussed and with that the claim that projection variability correlates with the ease with which their complement can be focused. Beginning with verbal triggers, especially cognitive factives like know, and cognitive change of state verbs like discover have been found to be fairly easily suspendable. Abrusán (2016) claims that this is because their complements, and with that their presupposition, can easily be focused. Consequently, the content of the complement can easily become the secondary main point, leading to presupposition suspension, as was illustrated above, see (48). In contrast, presuppositions triggered by iteratives like too and again have an anaphoric component and are not expressed by a constituent. Thus, presuppositions triggered by iteratives are impossible to focus which prevents them from becoming the secondary main point and from being suspended. Moreover, the introduced approach can account for projection variability within the class of factives. For example, emotive factives like be annoyed that, regret, be happy that are predicted to be more projective than cognitive factives. This is because listeners are argued to direct their attention to the attitude holder when they interpret emotive factives which is why complements of emotives are less easy to focus than 
complements of cognitive factives and cognitive change of state verbs.

One crucial difference between Abrusán (2011) and Abrusán (2016) is the extent to which the prestate implication of stop is attested to be projective. Whereas Abrusán (2011) treats change of state verbs similar to factives, the latter postulates that the presupposition of stop should project more robustly.

(49) a. I notice you are chewing on your pencil. Have you recently stopped smoking?

b. ??? I notice you are chewing on your pencil. Have you stopped smoking?

Abrusán (2016) emphasises the problematic case of stop by discussing the often used example (49a), taken from Geurts (1995); Simons (2001). She argues that this rare example of presupposition suspension for stop, relies upon the presence and focusing of the adverb recently. By questioning the event times per se, such a focus placement would make any temporal entailment - the pre-state of stop inclusive - addressing the main point and leading to presupposition suspension. This argument is underlined by contrasting (49a) with (49b) where the adverb is missing and it is arguably more difficult to get a non-presuppositional reading. Independent from whether this claim is correct or not, it is important to stress that stop was again found to be an intricate case. Unfortunately, Abrusán (2016) does not make assumptions about why this is the case. One reason may be the feature of stop to entail information about two independent, non-overlapping time intervals by default.

Although only discourse structure in form of focus placement has been illustrated, both accounts argue that there are more top-down factors converging on presupposition projection. In the upcoming section, Abrusán (2011, 2016) will be contrasted with empirical findings in order to (i) illustrate its superiority to other theoretical accounts and (ii) to emphasise why stop is still a problematic case.

\section{Predictions}

1. Default main point: if there is no context or other top-down factor (e.g. world knowledge) that may influence projection, presuppositions are predicted to project.

2. Secondary main point: Context, and more specifically the influence of discourse structure (focus): 


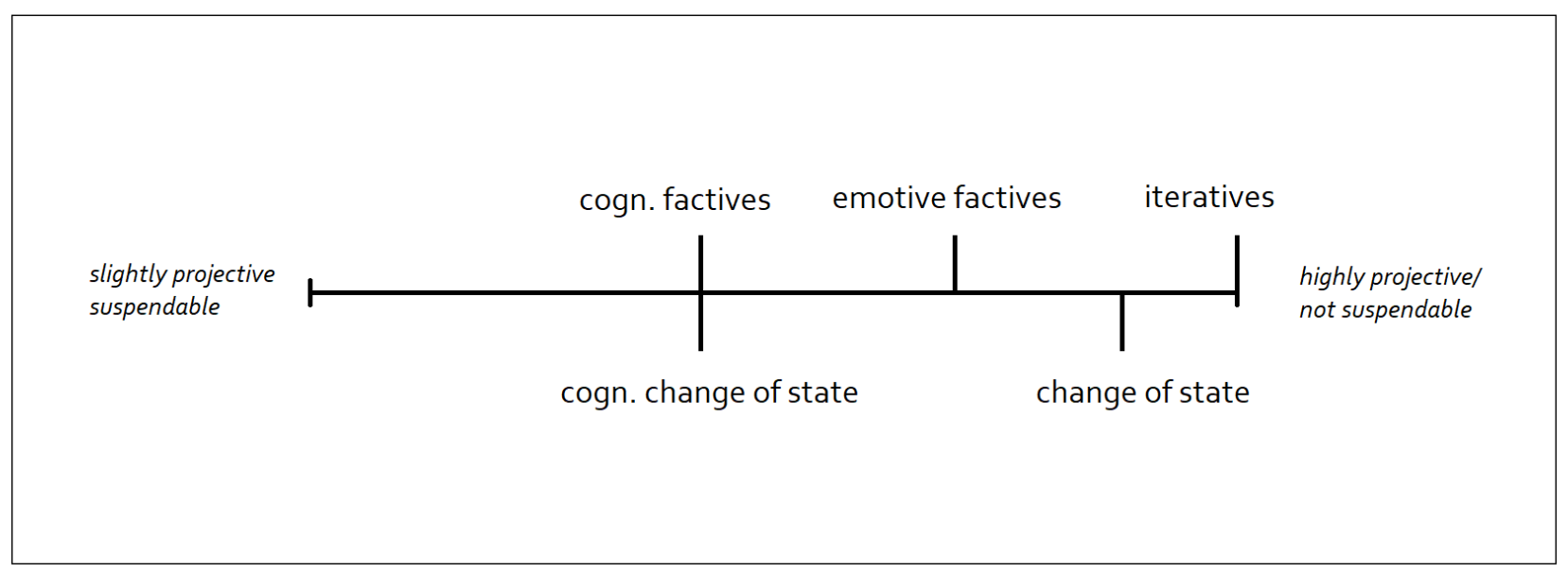

\subsubsection{All in one!}

This section will be concerned with the recently conducted study by Tonhauser et al. (2018) where a wide range of presupposition triggers were investigated, enabling a direct comparison between their empirical findings and Abrusán (2011, 2016)'s predictions. Tonhauser et al. (2018) investigated projection variability for presupposition triggers embedded under the polar question operator, among others, cognitive factives (e.g. know), emotive factives (e.g. to be annoyed that), cognitive change of state verbs (e.g. discover), and the change of state verb stop. The main goal of this study was to examine their hypothesis - called the Gradient Projection Principle - which states that projectivity correlates with at-issueness: the more at-issue a content is, the less likely that content is said to project. Their findings showed that, in accordance with Abrusán (2011, 2016), projectivity varies between presupposition triggers, also within the seemingly homogeneous group of factives. Most importantly, stop was found to project less robustly than claimed by Abrusán (2016), but again, deviated from other presupposition triggers in some respect.

The study consisted of two parts, one where projectivity and at-issueness were examined as withinsubjects factors, and one where a second at-issueness diagnostic was investigated. For the first experiment, a block design was used, such that in one block participants had to give projectivity ratings, and in the other at-issueness was assessed. The block order was randomized. Projectivity was measured by assessing speaker-commitment, see example (50).

a. Paul asks: Did Mary's daughter stop biting her nails?

Is Paul certain that Mary's daughter stopped biting her nails?

Participants had to adjust a slider labelled 'no' and 'yes' on the endpoints. The less participants judged the speaker to be certain about the presupposition, the less projective the content was taken 
to be. At-issueness was measured by asking whether participants think that the speaker addressed the presupposition with his/her question, see (51).

a. Paul asks: Did Mary's daughter stop biting her nails?

Is Paul asking whether Mary's daughter used to bite her nails?

Responses were given on a slider with 'no' and 'yes' on either end. 'No' was taken to mean that the presupposition was not at-issue.

The design allowed to investigate the Gradient Projection Principle within subjects, more specifically, whether participants who rated content to be not-at-issue, more likely assessed that the speaker was committed to that content. Furthermore, each presupposition trigger was used in three different experimental items, so that variations between lexical contents could be investigated. For example, stop was part of the experimental items Did Jack stop playing outside with the kids?, Has Mary's daughter stopped biting her nails? and Did Ann stop dancing ballet?, such that the projectivity of the lexical contents Jack used to play outside with the kids, Mary's daughter used to bite her nails, and Ann used to dance ballet could be compared. The findings for the first experiment showed that projectivity varied between emotive and cognitive factives - emotive factives like be annoyed that were significantly more projective than the cognitive factive discover which corresponds with Abrusán (2016)'s predictions. Furthermore, Tonhauser et al. (2018) found also projection variability for stop between subjects and experimental items, indicating that the presupposition of stop might not be as robust as was claimed by Abrusán (2016) and other accounts that characterised stop as being a 'hard core' trigger. In fact, the projectivity of stop patterned with the one of discover and was significantly less projective than emotive factives and the cognitive factive know. Furthermore, stop received the highest mean at-issueness ratings together with only.

These findings changed for the dialogue at-issueness diagnostic that was used in the second experiment. Since the first at-issueness diagnostic was based on a slightly different understanding/definition as the commonly established one, the second experiment was conducted to proof the validity of the first diagnostic.

(52) a. Paul: Mary's daughter stopped biting her nails.

b. Carla: Are you sure?

c. Paul: Yes, I am sure that Mary's daughter used to bite her nails.

Did Paul answer Carla's question?

In (52), the extent to which an answer satisfies a proceeding question was measured. Responses were given on a slider with 'no' and 'yes' on either side, whereby a 'no' response was interpreted to mean that the presupposition was not at-issue. The second diagnostic is based on the at-issueness definition that was introduced in the proceeding section 2.2.1. Here, at-issueness is measured by the 
extent to which content is up for debate which patterns with Abrusán (2011, 2016)'s understanding of attention-shift via focus placement. ${ }^{6}$ For the second at-issueness ratings, the presupposition of stop was found to be less at-issue than the complements of know and discover. Recall, that the presupposition of stop received the highest at-issueness ratings after only in the first experiment. Thus, stop was the only trigger that behaved differently between the two at-issueness diagnostics. The general findings of Tonhauser et al. (2018) correspond to Abrusán (2016)'s predictions, with one exception: the projection variability of stop. One objection when comparing Tonhauser et al. (2018)'s experimental design and Abrusán (2016)'s predictions, is that there was no discourse structure or context information that could explain attention shifts. In Abrusán (2011, 2016), it was claimed that by default without considering contextual influences, the presupposition is predicted to be accommodated globally, implying that there should not be any projection variability. This predictions is in accordance with Heim (1983) who stated that presuppositions should be accommodated globally when there is no context that could license local accommodation. However, there is a crucial difference between these two accounts. Abrusán (2016) emphasises that those factors that may shift attention, have yet to be determined, implying that listeners do not only use a local context when interpreting utterances. In similar vein, Tonhauser et al. (2018) pointed out that at-issueness alone could not explain projection variability between lexical contents within one presupposition trigger, arguing that world knowledge may be a crucial factor. The next section will introduce what is subsumed under the cover term 'world knowledge', and how this factor possibly influences projectivity.

\subsection{World knowledge}

\subsubsection{The Rational Speech Act model}

So far, presupposition projection was established to depend on local contexts, discourse structure and the presupposition type. However, from a conversational perspective there are even more factors to be considered: On what grounds do listeners evaluate utterances and in what way do their beliefs influence the inferences they make? In a conversation, listeners reason about what the speaker presumably knows to infer the meaning of an utterance. Similarly, the speaker assumes that the content he presupposes is already shared information, or at least, he behaves as if it is. Hence, speaker and listener engage in a recursive reasoning process to establish the common ground on which their utterances can be evaluated. The concept of understanding conversation as a recursive

\footnotetext{
${ }^{6}$ To rate at-issueness this way, can hint to which content participants paid attention to. For example, by placing focus on the constituent Mary's daughter, participants may be more likely inclined to rate that Paul answered Carla's question. Since here, the background question would have been Who stopped biting his/her nails?, constituting a secondary main point.
} 
reasoning process traces back to Grice (1975) but only recently found a revival with a framework that models understanding as Bayesian inference - the Rational Speech Act framework (Franke \& Jäger, 2016; Goodman \& Frank, 2016). The model captures the inference process of a pragmatic listener who has a speaker and literal listener in mind and reasons about them. Crucially, the model provides a way to formalise the distinctions of what a speaker knows, what a listener knows, what a listener thinks a speaker knows, etc. However, a further advantage of the RSA model is that it takes listener's world knowledge into account by using the Bayes' theorem. World knowledge may enter the inference process in form of prior probabilities of events. In what follows, the standard RSA model will be introduced briefly to set a basic understanding about the way in which prior probabilities enter the models' calculation. Subsequent sections will discuss possible influences that prior beliefs may have on listeners' inference based on claims that were recently made by Stevens et al. (2017); Tonhauser et al. (2018) and possible prior-overestimations (Degen, Tessler \& Goodman, 2015).

The RSA model consists of three levels: (1) the pragmatic listener who reasons about a speaker, (2) a speaker who reasons about a literal listener, and (3) a literal listener. Speaker and literal listener are not meant to simulate actual human beings but are part of the pragmatic listeners' psychology. In our example, the speaker Simon responds with his utterance to our pragmatic listener Lisa who simulates a version of Simon who she imagines to reason about a naive simulation of herself. Lisa infers Simon's intended meaning by determining the most likely world state $s$ given an utterance $u$. A world state may be understood as a possible answer to a discourse question, such as How many chalk sticks did Johannes steal?. Assuming that there are only three chalk sticks in question, one may assume a set of world states $S=\left\{s_{0}, s_{1}, s_{2}, s_{3}\right\}$, where the subscript stands for the number of stolen chalk sticks. Moreover, a set of alternative utterances $\mathrm{U}$ is specified, $U=\left\{u_{\text {all }}, u_{\text {none }}, u_{\text {some }}\right\}$, Johannes stole all/none/some of the chalk sticks. ${ }^{7}$ Each utterance has its' usual literal meaning: $\llbracket u_{\text {all }} \rrbracket=\left\{s_{i} \mid i=3\right\}, \llbracket u_{\text {none }} \rrbracket=\left\{s_{i} \mid i=0\right\}, \llbracket u_{\text {some }} \rrbracket=\left\{s_{i} \mid i>0\right\}$. Based on the utterances' literal meaning, there are two utterances that may denote $s_{3}$, i.e. $u_{\text {some }}$ and $u_{\text {all }}$. However, it is known that some gives rise to a scalar implicature, such that listeners infer that $u_{\text {some }}$ means some but not all $\left(s_{1}, s_{2}\right)$, instead of some and possibly all $\left(s_{1}, s_{2}, s_{3}\right)$. The standard explanation is that listeners infer a meaning beyond the literal meaning by considering that there would have been a stronger quantifier, namely all to uniquely identify a world state where three chalk sticks had been stolen $\left(s_{3}\right)$. This line of argumentation may be captured by the RSA model and will be used as illustration of the model's set-up. See below, the three levels and corresponding equations (e.g. Goodman \& Frank, 2016).

\footnotetext{
${ }^{7}$ The set of alternative utterances is an over-simplification. In reality, such a set would be undefinable, since there are infinite many ways of communicating a particular world state. For example a speaker may denote the specific number of stolen chalk sticks (Johannes stole 0/1/2/3 chalk sticks.). For the sake of brevity, it is assumed that the speaker had not enough time to count the chalk sticks.
} 
Literal Listener $\left(\mathbf{L}_{0}\right): P_{L_{0}}(s \mid u) \propto \llbracket u \rrbracket(s) \times P(s)$

The literal listener which is a naive version of Lisa, conditions on the truth of an utterance applied to a certain world state and takes the prior probability of that world state into account $(P(s))$. Thereby, the literal listener evaluates all possible utterance-world state-matches. For $u_{\text {some }}$, the literal listener rules out the world state $s_{0}$, since $u_{\text {some }}$ excludes $n=0$, and returns $s_{1}, s_{2}, s_{3}$, since $u_{\text {some }}$ entails $n>0$. The posterior probability $P_{L_{0}}\left(s_{i} \mid u_{\text {some }}\right)$ is proportional to the product of the truth values $1 / 0$ and the prior probability of $s_{i},\left(P\left(s_{i}\right)\right)$. This means that $s_{1}, s_{2}, s_{3}$ enter the subsequent equations with equal probability, assuming that they had been a priori equally likely. For $u_{a l l}$, the literal listener places all probability on $s_{3}$, since all only entails $n=3$.

Speaker $\left(\mathbf{S}_{1}\right): P_{S_{1}}(u \mid s) \propto \exp \left(\alpha \times\left(\log \left(L_{0}(s \mid u)\right)-C(u)\right)\right)$

The pragmatic listener extends the literal meaning by rationalising a speaker, i.e. a simulation of Simon, who in turn reasons about the literal listener. The speaker chooses an utterance out of the space of alternative utterances, the set $U$, to communicate a particular world state to the literal listener. The speaker simulates possible choices/actions under the premise to choose utterances in proportion to their utility: The speaker wants to communicate efficiently, and similarly wants to minimise the effort of the literal listener to arrive at the actual world state given the chosen utterance. Hence, utility is basically the trade-off between Grice (1975)'s maxims of quality and quantity. Quantity may be formalised by utterance costs $C(u)$, e.g. instantiated by word length/time that is needed to utter a sentence. Quality is formalised as negative surprisal/positive log probability of the actual world state for the literal listener which directly mirrors the utterances' informativity. The extent to which the speaker maximises utility is determined by the optimality parameter $\alpha>0$. Back to our example, if the speaker would have want to communicate $s_{3}$, the probability to chose $u_{\text {all }}$ is higher than the one of choosing $u_{\text {some }}$, since $u_{\text {all }}$ has a higher utility than $u_{\text {some }}$. This is because both are assumed to have the same utterance costs (same number of content words) and because the negative surprisal of $P_{S_{1}}\left(s_{3} \mid u_{\text {some }}\right)$ is greater than the one of $P_{S_{1}}\left(s_{3} \mid u_{a l l}\right)$.

Pragmatic Listener $\left(\mathbf{L}_{1}\right): P_{L_{1}}(s \mid u) \propto P_{S_{1}}(u \mid s) \times P(s)$

The pragmatic listener (Lisa) outputs a probability for each world state proportional to the product of the probability that the speaker chose a certain utterance to communicate the actual state and the prior probability of that state. In our example, the probability $P_{L_{1}}\left(s_{1 / 2} \mid u_{\text {some }}\right)$ is higher than the probability $P_{L_{1}}\left(s_{3} \mid u_{\text {some }}\right)$, based on the speaker's most likely choice of $u$ given $s_{3}$ which was $u_{\text {all }}$. Informally speaking, the pragmatic listener assumes that the speaker is rational (informative, precise) and would have chosen $u_{\text {all }}$ to denote $s_{3}$. Hence, he would not have chosen $u_{\text {some }}$ to denote $s_{3}$, since $u_{\text {all }}$ uniquely identifies $s_{3}$, and is, thus, more informative than $u_{\text {some }}$. Therefore, the reading 
some but not all chalk sticks have been stolen is the most likely reading of $u_{\text {some }}$.

\subsubsection{Prior beliefs}

A defining feature of capturing language understanding as Bayesian inference is that world knowledge in form of prior beliefs may affect listeners' inferences. Prior beliefs may enter the RSA model as probabilities of world states that are associated with them before new evidence was obtained. Evidence is supplied by utterances and their literal meaning. Prior probabilities of world states enter the model's equation on two levels: the literal and pragmatic listener level. In the example on scalar implicatures above, it was assumed that each world state was equally likely. Informally speaking, Lisa believed that there was no world state more likely than the other. This means that the posterior probability of $s_{1}$ and $s_{2}$ conditioned on $u_{\text {some }}$ was of the same size; $P_{L_{1}}\left(s_{1} \mid u_{\text {some }}\right)=P_{L_{1}}\left(s_{2} \mid u_{\text {some }}\right)$. If Lisa had have stronger beliefs about $s_{2}$, such that the prior probability of $s_{2}$ had been larger than the prior probability of $s_{1}$, then the posterior probability of $s_{2}$ given $u_{\text {some }}$ would have exceeded the one of $s_{1} ; P_{L_{1}}\left(s_{1} \mid u_{\text {some }}\right)<P_{L_{1}}\left(s_{2} \mid u_{\text {some }}\right)$. Hence, prior probabilities of events may impact the outcome in predicting inferences. The drawback of using uniform prior beliefs may be exemplified with Stevens et al. (2017)'s study. They investigated the extend to which prosody may predict the projection behaviour of manner adverb utterances under negation within the RSA framework. Taking a close look at the object under investigation, the adverb utterance (53), taken from Stevens et al. (2017, p. 1), entails that Masha ran.

$$
\text { Masha ran quickly. }
$$

This was predicted to also hold for (54a), where the content ought to project over the scope of negation. The probability of the content to project, was claimed to decrease for (54b) where prosody evokes a set of alternatives where someone but not necessarily Masha ran. Thus, participants were predicted to take the speaker to be less committed to the content that Masha ran in (54a) than for (54b).
a. Masha didn't run QUICKLY.

b. MASHA didn't run quickly.

In accordance with these predictions, Stevens et al. (2017) found that participants rated speaker commitment significantly higher for cases like (54a) than (54b). ${ }^{8}$ However, by only using prosody as only predictor and assuming uniform priors over world states, their Bayesian model failed to account for projection variability between experimental items. The authors acknowledged this fact

\footnotetext{
${ }^{8}$ Their results are in coherence with the discussed findings of Cummins and Rohde (2015); Tonhauser (2016) in section 2.2.2 and can be seen as evidence for Simons et al. (2010, 2016)'s account.
} 
and claimed that the model's performance could be enhanced by taking listeners' prior expectations about the projective content into account. Particularly, how likely listeners expect that Masha ran when they know that she didn't run quickly. A priori more likely events are assumed to project more likely.

The same claim was only recently made by Tonhauser et al. (2018) who investigated projection variability in correlation with at-issueness for a wide range of presupposition triggers, all embedded under a polar question operator. Besides finding differences between the projectivity of presupposition triggers, they found that projectivity varied also between the presupposition's lexical contents, which particularly applied to the trigger stop. The authors explain this between-lexical contentvariability, similar to Stevens et al. (2017), in terms of subjective prior probabilities of events. For illustration consider the presupposition trigger discover as example, taken from Tonhauser et al. (2018):

a. Did Bill discover that Alexander flew to New York?

b. Did Bill discover that Alexander flew to the moon?

Opposed to the lexical content Alexander flew to New York (55a), in (55b) the presupposition's lexical content Alexander flew to the moon denotes a highly unlikely event. In similar vein as Stevens et al. (2017), one may therefore argue that listeners take the speaker to be less committed to the presupposition in (55b) than in (55a). Thus, listeners less likely infer that Alex flew indeed to the moon than inferring that he flew indeed to New York. To sum up: prior probabilities may be an important factor in predicting projectivity, however, this claim is yet to be investigated.

What kind of prior beliefs do listeners presumably use when they encounter utterances containing stop? Listeners' expectations about the presupposition of stop, as conveyed by (56.a), entail their beliefs about an individual (Ralf) having a certain occupation (working as a plumber). His identity, to be male and to work as a plumber, may be contrasted with (56.b) where it is Ann instead of Ralf who is associated with the occupation plumber; or (57) where Ralf stopped working as a beautician. Although not impossible, both (56.b), or (57), seem to be less common cases than (56.a).

(56) Did a. Ralf/b. Ann stop working as a plumber?

(57) Did Ralf stop working as a beautician?

The influence of world knowledge on listeners' production and comprehension in form of gender stereotypes is well known. For example, listeners were found to be surprised when they encountered pronouns or reflexives that violated their expected gender stereotype, e.g. when she/herself referred to surgeon (e.g. Sturt, 2003). In similar vein, von der Malsburg, Poppels and Levy (2017) found a bias against female pronouns to denote the prospective U.S. president during the past election 
cycle, e.g. The president..., she/he..., in production and comprehension. Boyce et al. (2018) extended von der Malsburg et al. (2017)'s findings and found a bias against female pronouns in production, but not in comprehension, for a variety of role nouns, e.g. plumber, priest, beautician, nanny. In fact, Boyce et al. (2018) supply the facts to the mentioned intuitions above (56-57): Listeners' beliefs-system contains more or less strong gender stereotypes. More specifically, they conducted a norming study on 80 role nouns. Participants were asked to rate 'how likely female' (26 participants), or 'how likely male' (27 participants) a given role noun was in their opinion. Their findings illustrated that the strength of gender stereotypes associated with role nouns may be assembled on a continuum. For example, plumber was rated to be male with a probability of 0.8 , and beautician was rated to be female with a probability of 0.79 . Role nouns such as clerk, baker, acrobat, were judged to be likewise likely to be female or male. Evidently, listeners have particular gender stereotypes in mind. Is it possible that these strong believes influence the processing of presuppositions? If so, and in vein with Stevens et al. (2017); Tonhauser et al. (2018)'s reasoning, listeners may assess that a speaker who utters (56.a) is more committed to the presupposition's lexical content than a speaker who uttered (56.b), and thereby, listeners are more likely inclined to understand that the speaker presupposed that Ralf used to work as a plumber than to believe that the speaker presupposed that Ann used to work as a plumber. This implies that the lexical content of (56.a) might be more likely to project than the one of (56.b).

\section{Predictions}

- The more likely lexical content is, the higher the projectivity of that content. 


\section{Chapter 3}

\section{Empirical Part}

As has become clear in the previous chapter, presuppositions vary in the extent to which they are projective. The attested projection variability speaks against a categorical distinction between content that projects and content that does not, as was suggested by Heim (1983) as well as Simons et al. (2010, 2016). It was rather Abrusán (2011, 2016)'s account that explained projection variability between presuppositions in a compelling manner. Recall that projection variability was introduced earlier as projectivity, i.e. the probability of content to project. Projectivity captures that listeners have to decide between a presuppositional and a non-presuppositional interpretation under uncertainty, whereas the decision to presuppose content or not is still a binary one on speaker-level. Projection variability between presuppositions was claimed to arise due to those properties that tell presuppositions apart, however, the reason for differences between lexical contents of one presupposition has yet to be established. It was only claimed that these differences may be due to varying prior probabilities of events that are described by the lexical content.

Since prior investigations on the presupposition triggered by stop led to inconclusive results and intuitions about its projectivity, this presupposition will be the main object of investigation in the rest of this thesis. Whereas Zeevat (1992); Simons et al. (2010); Abrusán (2011) grouped stop together with factives, Kadmon (2001); Simons et al. (2016); Abrusán (2016) claimed that the presupposition triggered by stop is more projective than the ones triggered by factives. Besides empirical findings that illustrated that utterances with stop can in fact receive a non-presuppositional reading (Romoli \& Schwarz, 2015; Cummins et al., 2013), stop was often found to deviate from other triggers (Cummins \& Rohde, 2015; Tonhauser et al., 2018). Tonhauser et al. (2018)'s study offers a convincing comparison between stop and other presupposition triggers, suggesting that the presupposition triggered by stop patterns with the one of discover in projectivity, both being less projective than the presupposition triggered by know. Nonetheless, stop was the only presupposition trigger whose at-issueness ratings differed between at-issueness diagnostics, making it once more a 
highly complex and interesting case. One subsequent aim of this thesis is to replicate the findings on at-issueness of Tonhauser et al. (2018) and with that the predictions of the Gradient Projection Principle. Besides the evident influence of at-issueness on projectivity, at-issueness alone could not account for variations between lexical contents of one presupposition. Especially the lexical contents of stop differed from each other. Therefore, this study aims to test whether listeners' assessment of speaker commitment - and as such the projectivity of the presupposition of stop - is influenced by listeners' world knowledge in form of prior probabilities of events.

\subsection{Experiment}

\subsubsection{Gender stereotypes}

As was introduced in section 2.4.2, listeners' expectations about the pre-state content of stop often entail their beliefs about an individual (Amy/David) having a certain habit or occupation (to dance ballet). Would listeners take the speaker to be less committed to the presupposed content, if she/he had asked whether David instead of Amy stopped working as a ballet dancer? Do listeners' a priori beliefs about gender stereotypes - e.g. associating dancing ballet with a female individual — influence projection?

a. Did Amy stop working as a ballet dancer?

b. Did David stop working as a ballet dancer?

In this experiment, the influence of world knowledge on projectivity was examined by taking listeners' prior beliefs in the form of gender stereotypes into account. For this purpose, gender-biases associated with occupations like nanny, priest, gymnast, architect that had been collected by Boyce et al. (2018) were used as listeners' prior beliefs. Prior probabilities were expressed by the factor consistency, i.e. the extent to which the identity of an individual-being either male or female and having a certain occupation - supports the presupposition. The consistency measure is a value that ranges from 0 to 1 , where a value close to 0 means that the gender of an individual is inconsistent with a certain occupation, according to the collected gender-bias that was found to be associated with that occupation. A value close to 1 means that the gender of an individual is consistent with an occupation. The measure was derived from the already collected gender-bias values (where 0 meant male-biased and 1 female-biased), and the individual who was matched with that occupation - male $(-1)$ /female (1). For example, being a nanny was found to be biased towards being female with a value of 0.8 . Being matched with a male individual with the value -1 this led to the consistency measure of 0.2. Being matched with a female individual with the value 1 this led to the consistency measure of 0.8 . 
- Given a bias of 0.8 , and a female individual $(-1)$ : $[(0.8-1 / 2) *(-1)]+1 / 2=0.2$

- Given a bias of 0.8 , and a male individual $(1):[(0.8-1 / 2) * 1]+1 / 2=0.8$

In the present study, it was predicted that the less likely lexical content was a priori- the lower the consistency measure - the less likely that content should be said to project.

H1 The higher the consistency measure of a given lexical content, the more inclined are listeners to assess that the speaker is committed to that content (= the more likely that content is said to project)

The predictions for at-issueness is in accordance with Tonhauser et al. (2018)'s the Gradient Projection Principle which states that the more at-issue lexical content is, the less likely that content is said to project.

H2 The higher the at-issueness ratings of a given lexical content, the less likely listeners assess that the speaker is committed to that content (= the less likely that content is said to project).

\subsubsection{Design}

In order to explore these hypotheses, projectivity and at-issueness judgements for 40 lexical contents were collected. They came about by using a 20x2 design, with the factors occupation (20 occupations), and gender of the individual associated with that occupation (female/male). Both manipulations led to minimal pairs, where a certain occupation was either done by a male or female individual. The 20 occupations were chosen from the 80 role nouns that were investigated in Boyce et al. (2018)'s study. Half of them with a bias towards female, and the other half with a bias towards male, whereby the strength of biases varied. The factor gender was manipulated by either using unambiguously female or unambiguously male names. Names were randomly chosen out of a pool of frequent $\mathrm{AE} / \mathrm{BE}$ names and each name was only used once. Each participant saw only one of the 40 contents for which projectivity and at-issueness ratings were assessed, in order to explore the predicted correlation (H2) between at-issueness and projectivity ratings by considering by-subjects and by-items variability.

\begin{tabular}{l|l|l|l} 
Occupation & Gender of Name & Bias direction & Consistency \\
\hline \hline plumber & male & male & 0.8 \\
plumber & female & male & 0.2 \\
nanny & male & female & 0.2 \\
nanny & female & female & 0.8
\end{tabular}

Table 3.1: Experimental manipulation and corresponding consistency measure 
Furthermore, each lexical content received its corresponding consistency measure, illustrating whether the occupation-gender-match was consistent with the measured gender-bias or not, see table 3.1 for an example and 3.8 for all experimental items.

Similar to Tonhauser et al. (2018); Tonhauser (2016); Stevens et al. (2017), projectivity was measured as speaker commitment, whereby participants were asked to judge the extent to which a speaker was certain of presuppositions' lexical content. In example (59), the speaker is most likely not committed to the fact that it is raining outside.

(59) Speaker1: 'Is it raining outside?'

Is Speaker1 certain that it is raining outside?

The choice of measuring projectivity as speaker commitment in similar vein with the mentioned studies enables the direct comparison between studies. This also holds for at-issueness, which was measured as the extent to which lexical content of presuppositions is up for debate and addressable. More specifically, participants were asked to judge the extent to which an answer conveying the lexical content of presuppositions addressed a preceding 'Are you sure?' question. Content that is judged to be a possible response to the 'Are you sure?' question, as in (60), can be understood as being at-issue/under debate.

(60) Speaker1: 'Tim partied all night.'

Speaker2: 'Are you sure?'

Speaker1: 'Yes, I'm sure that Tim partied all night.'

Did Speaker1 answer Speaker2's question?

This operationalisation is based on an already established concept that was assumed by the majority of studies on at-issuenes, such as Cummins et al. (2013); Cummins and Rohde (2015); Tonhauser (2016). In this way, the findings of this thesis are made comparable to a wide range of studies.

\subsubsection{Materials}

Experimental items for projectivity were questions of the form 'Did X stop working as a Y?', where $\mathrm{X}$ denotes a female or male individual and Y one of the 20 occupations, see (61) for an example.

(61) Ryan: 'Did Linda/James stop working as a plumber?' Is Ryan certain that Linda/James used to work as a plumber?

Utterances were presented on black-white pictures. Each picture had the same party-setting in the background and two persons in the foreground, whereby one of them was the speaker and one of them the listener. The gender of speaker and listener was counterbalanced across experimental 
items, such that the speaker was sometimes male, sometimes female, talking to a person of the same or different gender (resulting in four different speaker-listener matches). For illustration, see the experimental items corresponding to the occupation 'plumber': in 3.1 the individual associated with working as a plumber is female, see the Appendix 3.8 for the male version.

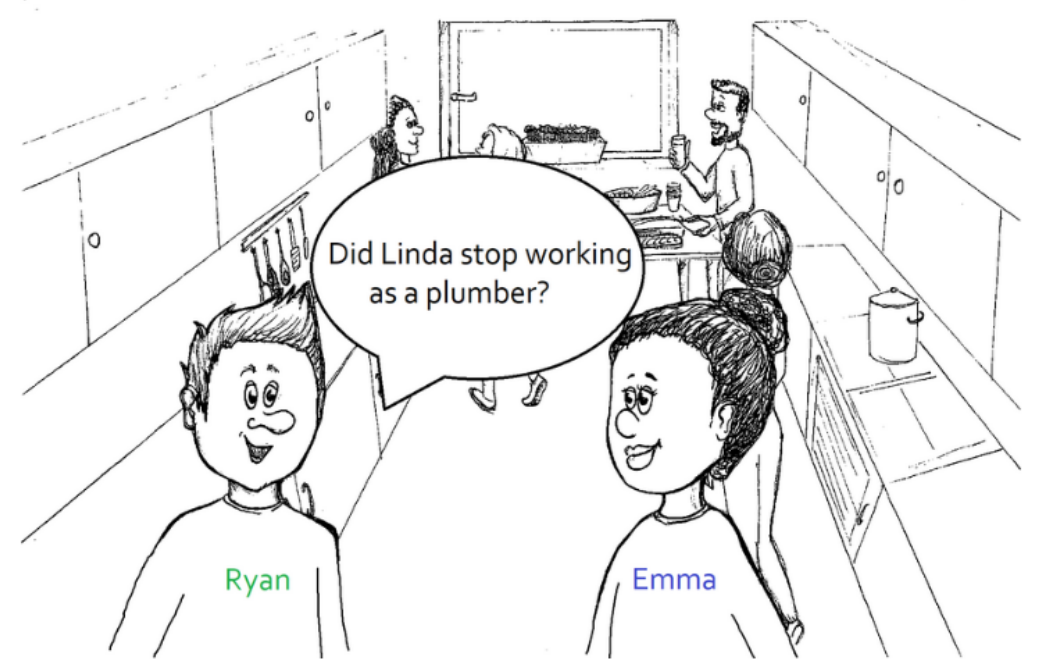

Is Ryan certain that Linda used to work as a plumber?

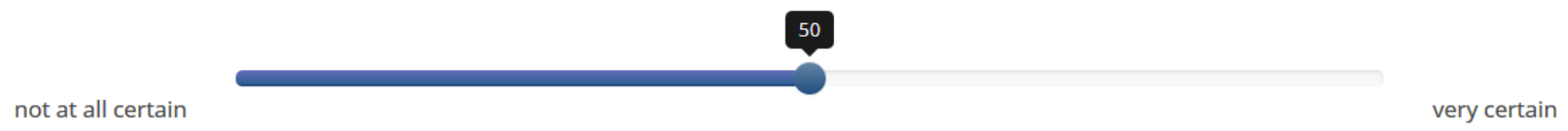

Figure 3.1: Experimental item for 'plumber'/female (Projectivity)

Projectivity was measured by asking participants to assess the extent to which a speaker is certain about the lexical content of a presupposition by adjusting a slider labelled 'not at all certain' and 'very certain' on each end. A response close to 'not at all certain' was taken to indicate that the content is unlikely to project with a probability of 0 , and a response close to 'very certain' that the content is likely to project with a probability of 1 . 

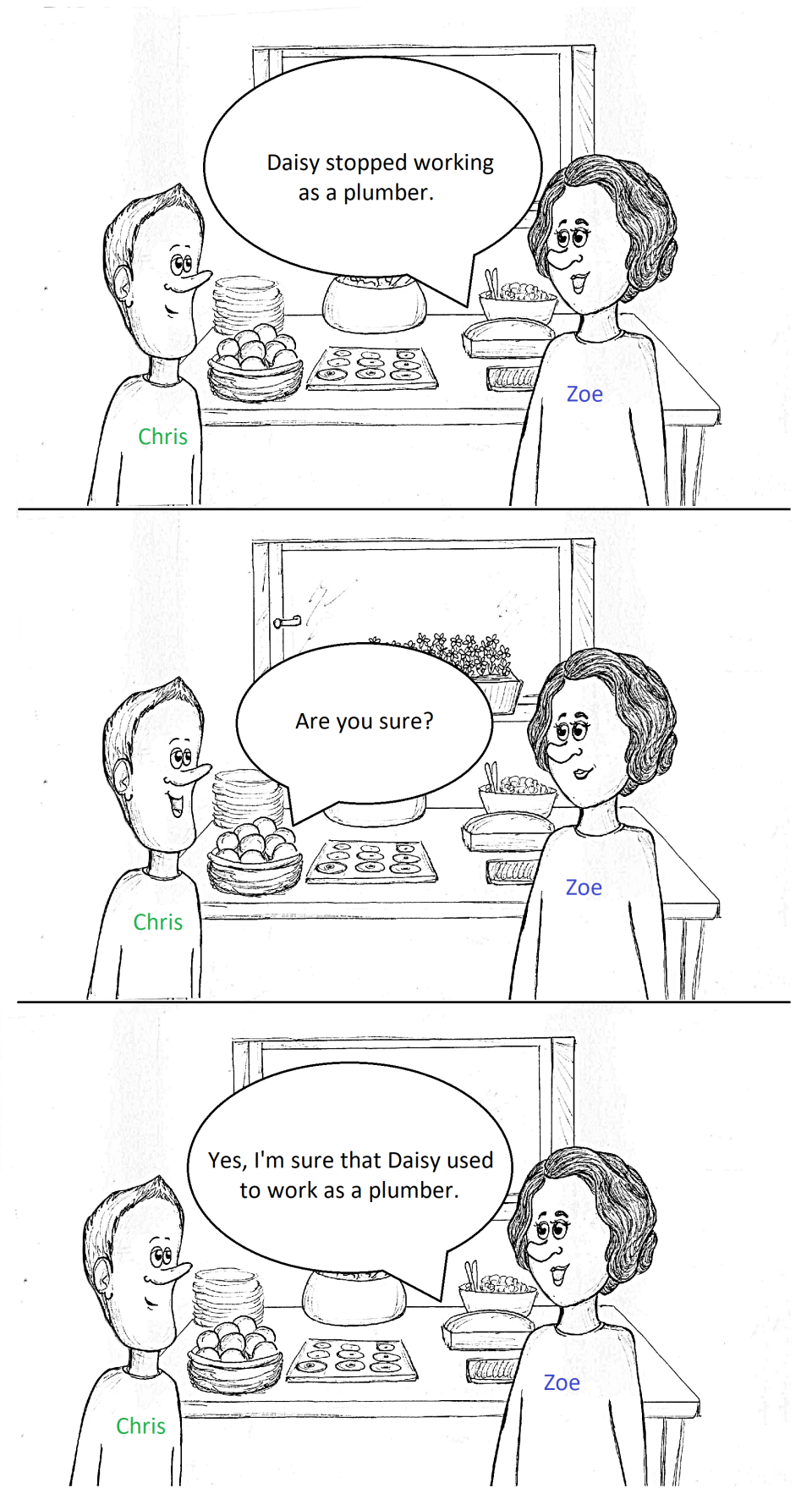

Did Zoe answer Chris 's question?

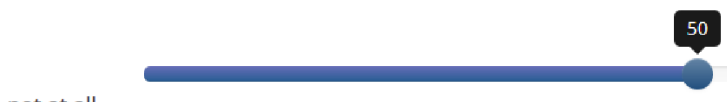

definitely yes

Figure 3.2: Experimental item for 'plumber'/female (At-issueness) 
Experimental items for at-issueness ratings were three-turn dialogues. During the three-turn dialogue, Speaker1 first made a statement of the form ' $\mathrm{X}$ stopped working as a Y.', where $\mathrm{X}$ denoted either a female or male individual and Y one of the 20 occupations. Then Speaker2 asked 'Are you sure?', and Speaker1 responded by verifying the presupposition: 'Yes, I'm sure that X used to work as a Y.', see (62).

(62) Zoe: 'Linda/James stopped working as a plumber.'

Chris: 'Are you sure?'

Zoe: 'Yes, I'm sure that Linda/James used to work as a plumber.'

Did Zoe answer Chris's question?

Experimental items for at-issueness were also presented on black-white pictures, whereby each conversational turn was illustrated by one picture. The same party-setting as background was used for all experimental items. Crucially, background setting, speakers, and the person that Speaker1 and Speaker2 talked about, were purposely chosen to be different from the one used for the projectivity items. This was done to prevent participants from construing a discourse between projectivity and at-issueness items. ${ }^{1}$ Again, the gender of both speakers was counterbalanced. For illustration, see 3.2 where the individual associated with working as a plumber is female, and the Appendix for the male version 3.9. At-issueness was measured by asking participants to asses whether they think that the speaker responded accordingly to a preceding 'Are you sure?' question. Participants had to adjust a slider labelled with 'not at all' and 'definitely yes' on each end. A response of 'not at all' was taken to mean that the content was not-at-issue, and 'definitely yes' that the content was at-issue.

Besides experimental items, two control items (63a-63b) served to check whether participants understood the task. Furthermore, two items (63c-63d) containing the presupposition trigger discover were used as fillers.

a. Is Tim a vegetarian?

Maria is a vegetarian. // Are you sure? // Yes, I'm sure that Maria is a vegetarian.

b. Did Johanna bring cookies?

Titus brought cookies. // Are you sure? // Yes, I'm sure that Titus brought cookies.

c. Did Lisa discover that Dani lived in Berlin?

Doreen discovered that Malte lived in Berlin. // Are you sure? // Yes, I'm sure that Malte lived in Berlin.

\footnotetext{
${ }^{1}$ Comments in a pre-test showed that participants often tried to answer the question 'Did Speaker1 answer Speaker2's question?' with respect to preceding projectivity items when they noticed that the same speaker, listener and person-occupation match was used.
} 
d. Did Martin discover that Alex flew to the moon?

Paul discovered that Carla flew to the moon. // Are you sure? // Yes, I'm sure that Carla flew to the moon.

Regarding the projectivity ratings of control items, participants were expected to assess that the speaker is not totally certain that Tim is a vegetarian (63a) or that Johanna brought cookies (63b). The same goes for at-issueness ratings, such that Speaker2 should be judged to mostly answer Speaker2's question.

\subsubsection{Participants and Procedure}

The experiment was implemented using the open source on-line statistical survey web app LimeSurvey (Limesurvey, 2003-2018). 400 participants were recruited over the crowd-sourcing platform Prolific and 37 additional participants were recruited over social media. Participants' age ranged from 18 to 78, with a mean age of 31.5. 194 participants responded to be female, 237 male, and 4 participants chose the option 'Other'. The procedure started by using a generic context, taken from (Tonhauser et al., 2018), which said participants to imagine that they are at a party and overhear conversations:

Imagine that you are at a party and that, upon walking into the kitchen, you overhear people talking. In what follows, you will see pictures about different kinds of conversations you may have overheard. Your task is to answer a simple question about each of these conversations by providing ratings on a sliding scale. Please pay close attention to the task.

Besides this context, utterances were presented in isolation. The experiment proceeded in two blocks, first the projectivity block ('certain that' task), second the at-issueness block ('Are you sure?' task). In each block one experimental item, two control items and two fillers were presented to participants, such that each participant had to rate 10 pictures in total. Crucially, participants rated projectivity and at-issueness for the same occupation-gender manipulation. For example, one participant would see first 3.1 together with two control items and two fillers, and then 3.2 with two control items and two fillers. At the end of the experiment participants were asked to give additional information about their age, gender, and level of education on an optional basis. The experiment took approximately five minutes. 


\subsection{Results}

\subsubsection{Projection variability across contents}

Observing the data showed that, in line with Tonhauser et al. (2018)'s results, projectivty ratings varied greatly between lexical contents and between participants, see figure $3.3 .^{2}$

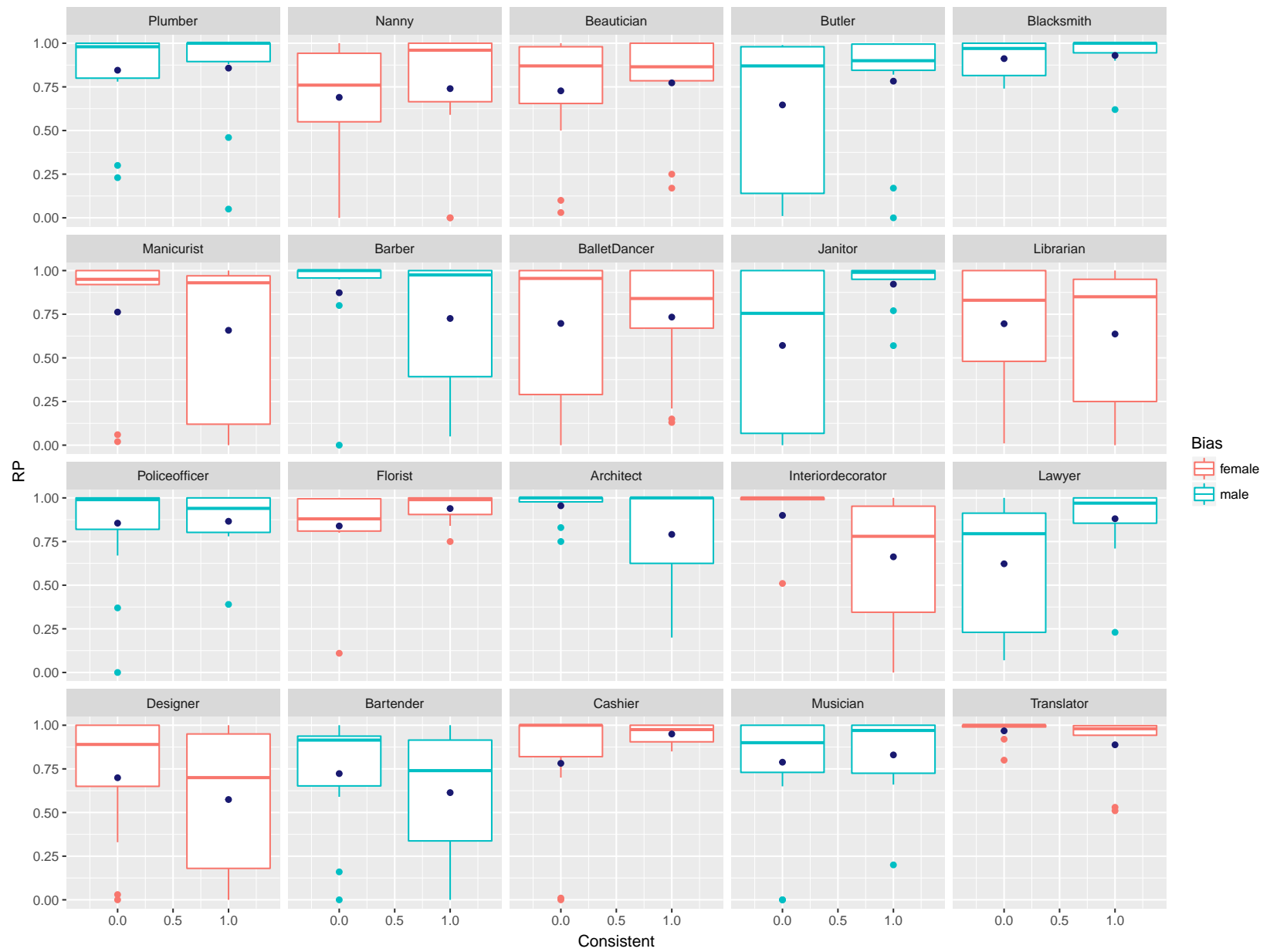

Figure 3.3: Boxplot for projectivity ratings per occupation, contrasting gender-occupation matches that are consistent with collected gender stereotypes (1), with those that are not (0). Blue bloxplots indicate an occupation associated with a male bias, whereas red boxplots indicate an occupations associated with female bias. Occupations are ordered in descending order, e.g. plumber associated with a strong gender bias come first and translator with almost no bias comes last.

\footnotetext{
${ }^{2}$ In this thesis data analysis and illustration was done using the statistical environment and language R (R Development Core Team, 2008). All plots were created by using the R package ggplot2 (Wickham, 2009).
} 
Here, projectivity ratings per occupation are visualised as boxplot, whereby occupations are ordered in descending order: occupations with the highest bias towards a particular gender, such as plumber come first, and translator with almost no associated gender bias comes last. Blue dots indicate mean ratings and notches median ratings. For each occupation the left boxplot (0) shows ratings for lexical contents that are inconsistent with the associated gender stereotype: e.g. the match between the occupation plumber and a female individual; whereas the right boxplot illustrates projection variability of consistent contents, indicated with 1: e.g. the match between the occupation plumber and male individual. The boxplots show that median ratings are often close to ceiling, suggesting that the majority of participants found the content highly projective. Nonetheless, this is not always the case, and mean ratings, box sizes and whisker lengths illustrate projection variability. However, there is no evident pattern across contents that mirrors differences between consistent and inconsistent lexical contents.

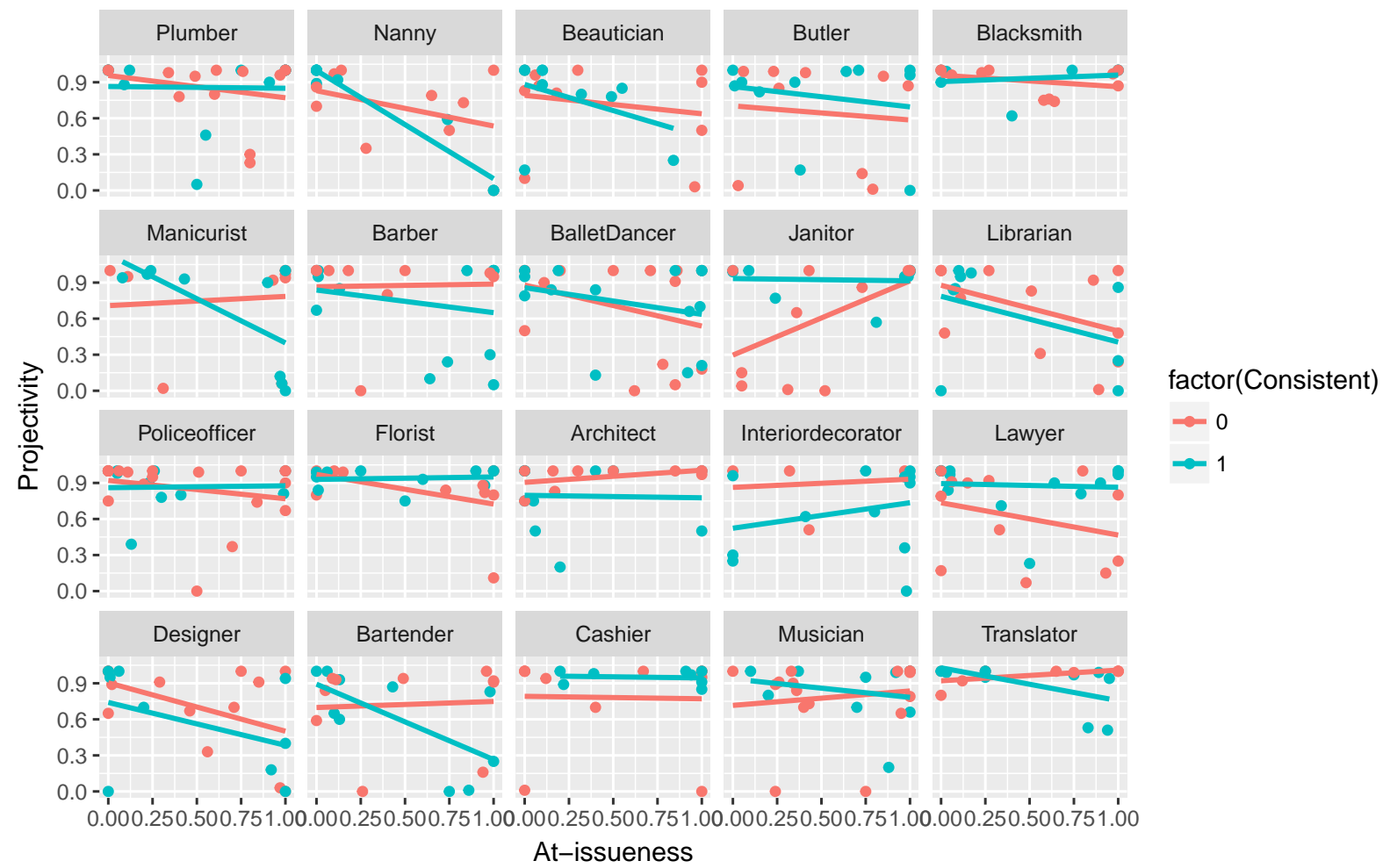

Figure 3.4: Projectivity ratings as a function of at-issueness ratings, per occupation and the factor of being consistent, whereby 0 means that the gender-occupation is inconsistent with collected gender stereotypes, and 1 means consistent with that stereotype. Occupations are ordered from occupations with high consistency measures (strong biases) in the first row to occupations with low consistency measures (weak biases) in the last row. 
This becomes even more apparent in figure 3.4, where projectivity ratings are plotted against at-issueness ratings for each occupation. The order of occupation remains in descending order. This time, the choice of colour distinguishes consistent content from inconsistent one: red points illustrate the ratings for lexical contents where the gender-occupation match was not consistent with the collected gender stereotype and blue points illustrate ratings for lexical contents where the gender-occupation match was consistent. For each occupation two regression lines were fitted to show the differences between consistent and inconsistent lexical contents. It becomes already evident that there is high variation between occupations and the way at-issueness and consistency affected projectivity ratings. Again, there is seemingly no evident pattern, e.g. that consistent lexical contents are regularly rated to be more projective.

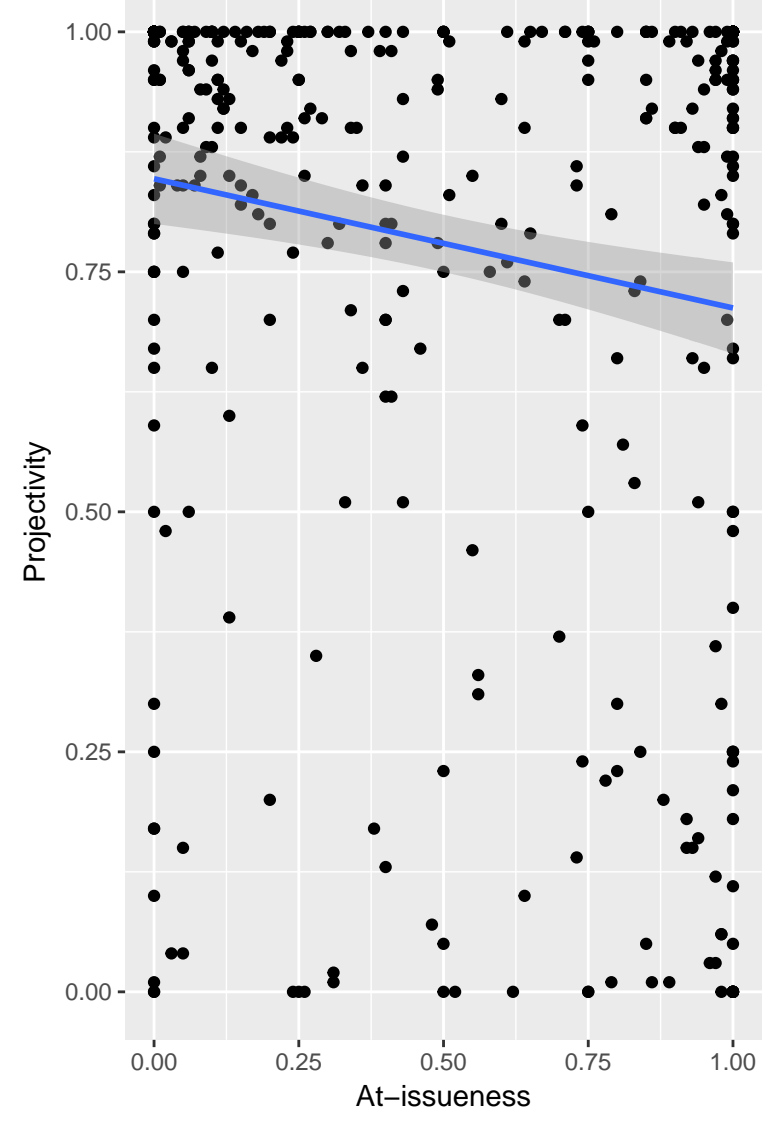

(a)

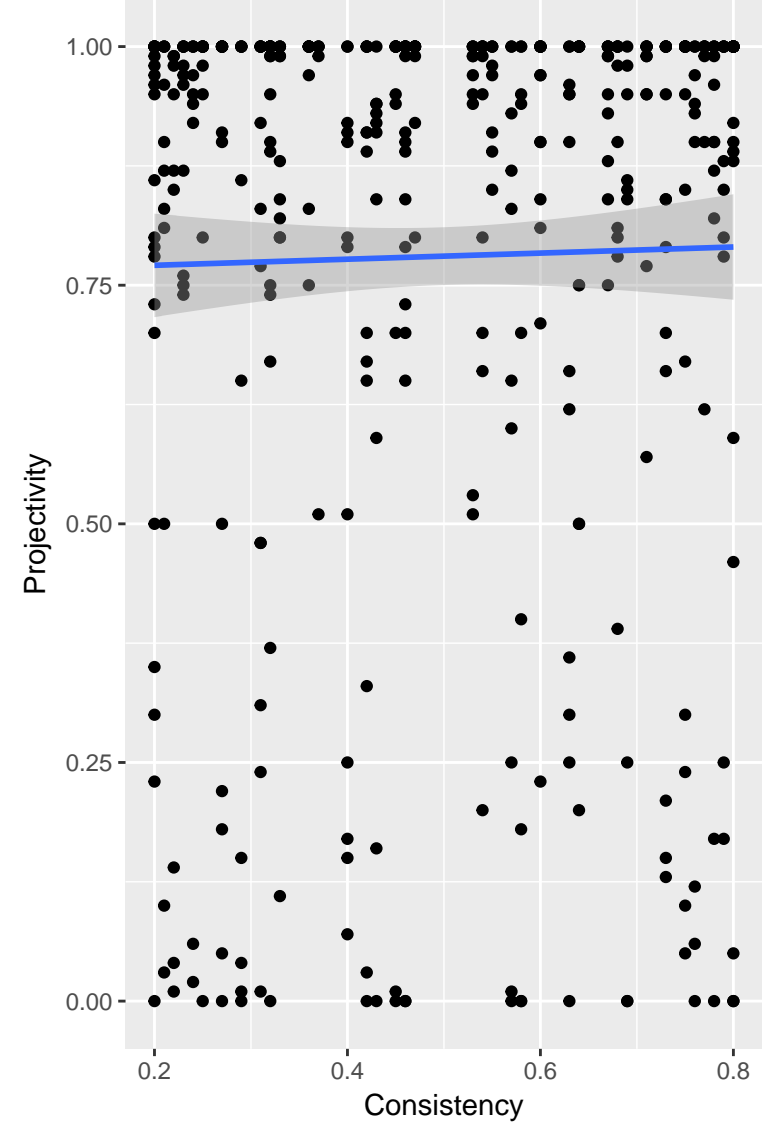

(b)

Figure 3.5: Projectivity ratings as function of at-issueness ratings (a) or consistency (b) averaging over lexical contents. The grey area presents 95\% Confidence Intervals. 
Averaging over lexical contents the following trends get apparent, see 3.5. Plot (a) suggests an effect of at-issueness: higher at-issueness ratings resulted in lower projectivity ratings. Plot (b) suggests a very small effect of consistency: the more consistent a content is with listeners' believes about gender stereotypes the more likely that content projects.

\subsubsection{At-issueness and Consistency}

A mixed-effect linear regression predicting projectivity rating from centred fixed effects of atissueness ratings and consistency measures was conducted using the lmer function from the $\mathrm{R}$ package lme4 (Bates, Mächler, Bolker \& Walker, 2015). The model included random effects such as random by-lexical contents intercepts, assuming differences between lexical contents, and by-lexical contents random effects slopes for consistency, assuming that the effect of consistency may vary across lexical contents. Further, random by-lexical content effects slopes for at-issueness were included, based on the assumption that also the effect of at-issueness differs between lexical contents. Since this model did not converge, random slopes had to be removed, remaining with a linear mixed effects model with random by-lexical contents intercepts. Since the residuals of the model were not normally distributed ${ }^{3}$ and did not vary equally around the regression line $(3.10,3.11,3.12)$, a parametric bootstrap was used to provide more sophisticated standard errors, confidence intervals using the R package boot (Davison \& Hinkley, 1997; Canty \& Ripley, 2017). Bootstrapped p-values were obtained by using likelihood ratio tests of the full model with the effect in question against a model without that effect using the $\mathrm{R}$ package pbkrtest (Halekoh \& Højsgaard, 2014). Parametric bootstrap is an approach of statistical inference where simulations are used to generate bootstrap samples from the assumed distribution of the data together with the estimated fixed effects and variance components (Morris, 2002; Fox \& Weisberg, 2011). ${ }^{4}$ Bootstap was performed using 2000 simulations.

\begin{tabular}{l|ccc||ccr} 
& Coefficients & SE & t-value & bias & Bootstrap SE & $95 \%$ CI's \\
\hline \hline Intercept & 0.78041 & 0.01750 & 44.591 & 0.00063 & 0.01807 & $(0.7443,0.8152)$ \\
At-issueness & -0.13733 & 0.03705 & -3.707 & 0.00061 & 0.03681 & $(-0.2101,-0.0658)$ \\
Consistency & 0.02793 & 0.08753 & 0.319 & 0.00005 & 0.08869 & $(-0.1459,0.2017)$
\end{tabular}

Table 3.2: Fixed effects, standard errors (SE) and t-values, together with estimated bias from bootstrap and bootstrapped standard errors (SE) and Confidence Intervals (CI)

The summary shows the original estimate of each coefficient and its standard error and t-value. The

\footnotetext{
${ }^{3}$ Log-transforming projectivity ratings improved the issue, but would have led to the exclusion of 20 data points where projectivity was rated to be zero. This is why the following analysis proceeded without transformation.

${ }^{4}$ Parametric bootstraps rely on the assumption that random effects are normally distributed (Morris, 2002). This assumption is fairly met, see 3.13.
} 
right hand-side of the table gives bootstrap estimates of bias, standard error (SE) and Confidence Interval (CI). The bias value is the difference between bootstrap and original sample value. The bootstrap standard errors and confidence intervals are computed from the bootstrap sample values. The bootstrap output gives similar standard errors as the model output with very small biases, suggesting that estimates from the model are reliable, despite the fact that residuals were not normally and equally distributed. To see histograms for bootstrapped fixed effects see 3.14. The t-values already show that only the effect of at-issueness reached significance $(\beta=-0.13733, \mathrm{SE}=0.03705$, $\mathrm{t}=-3.707)$. Additionally, a parametric bootstrap likelihood ratio test using 2000 samples was conducted, whereby models with effects in question and models without those effects were compared using the pbkrtest R package (Halekoh \& Højsgaard, 2014). The likelihood ratio test revealed that only the effect of at-issueness was significant with a p-value of 0.0005 . The intercept of 0.78 suggests that when lexical content is to some extent at-issue (average at-issueness 0.495) and more or less consistent (average consistency measure 0.495 ) that content is on average $78 \%$ likely to project. The significant main effect of at-issueness indicates that when at-issueness of content exceeds its average of 0.459 by 0.4 the probability of the presupposition to project decreases on average by $5.5 \%$, as long as the content is fairly consistent with gender stereotypes (average 0.459).

Consistency does not seem to have an effect on projectivity. This means that there was no evidence that prior beliefs in form of gender stereotypes affect listeners' understanding of presuppositions triggered by stop. However, the variability of projectivity ratings suggest that the presupposition triggered by stop may be subject to suspension even when there is no local context that could have licensed local accommodation. Further, the significant effect of at-issueness suggests that in line with the gradient projection principle (Tonhauser et al., 2018), lexical content projects to the extent to which it is not-at-issue.

\subsubsection{Bayesian Analysis}

In the second part of the analysis, a mixed-effects linear regression predicting projectivity ratings from centred fixed effects of at-issueness ratings and consistency measures was conducted within the Bayesian framework using the brm function from the R package brms (Bürkner, 2017, in press). This analysis made it possible to restrict the models' predictions to values between 0 and 1 . The specified model in section 3.2.2 made unreasonable predictions, since projectivity could exceed 1 and be negative. The Bayesian framework enables to define mixed effects models more flexibly, which means that this time random effects slopes for both effects, at-issueness and consistency, could be included. Recall that using the frequentist framework, as was done in the first analysis above, the model with a by-lexical content varying intercept and slope structure did not converge. A second advantage of the Bayesian framework is that the two formulated hypotheses can be tested directly: 
H1 The higher the consistency measure, the more likely that content is said to project, and thus, the effect of consistency on projectivity is predicted to be positive: $\beta>0$.

What is the posterior probability that the effect of consistency is greater than zero/positive?

H2 The higher the at-issueness ratings of a given lexical content, the more likely that content is said to project, and thus, the effect of at-issueness is predicted to be negative: $\beta<0$.

What is the posterior probability that the effect of at-issueness is less than zero/negative?

In Bayesian statistics, the goal is to obtain the posterior distributions of the estimated model parameters given prior knowledge, the data and the formulated model, such that the posterior distribution is estimated in terms of prior and likelihood:

\section{Posterior $\propto$ Prior $\times$ Likelihood}

The following paragraphs will elaborate on the choice of priors and likelihood.

Likelihood A beta distribution was chosen as likelihood for projectivity ratings. The beta distribution is suggested for data such as proportions and percentages which usually are heteroskedastic, i.e. show more variation around the mean than on lower and upper limits (Ferrari \& Cribari-Neto, 2004; Cribari-Neto \& Zeileis, 2010). Likewise, since the beta distribution is naturally asymmetrical, it can account for the asymmetrical distribution of the present data, while Gaussian-based approximations can lead to inaccurate approximations in this case (Ferrari \& Cribari-Neto, 2004). Since the beta distribution only allows values on the open standard unit interval $(0,1)$, projectivity ratings were transformed, such that they ranged from 0 to 1 excluding the extremes 0 and 1 . For example, projectivity ratings of 1 would be transformed to approximately 0.999 . The used transformation is based on the recommendations by Smithson and Verkuilen (2006), whereby y denotes the dependent variable and $n$ the sample size:

$$
\begin{gathered}
(y *(n-1)+0.5) / n \\
(1 *(438-1)+0.5) / 438=0.999
\end{gathered}
$$

\section{Priors}

- Intercept: Based on Tonhauser et al. (2018)'s findings on projectivity ratings for stop, a normal distribution with mean 0.87 and standard deviation 0.1 was used. This means that it is assumed with $68 \%$ certainty that the grand mean of projectivity ratings will lie between 0.77 and 0.97 . Since the standard deviation for the projectivity ratings of stop alone was not reported, a fairly conservative standard deviation was used. 
- At-issueness: Based on Tonhauser et al. (2018), a weakly informative prior for at-issueness was used, assuming that the effect of at-issueness will likely be negative. The effect size of at-issueness that was reported by Tonhauser et al. (2018) is not considered, since this is the effect averaged over a wide range of different presupposition triggers and not only for stop. A normal distribution with mean -0.5 and a standard deviation of 0.5 was used as prior. This means that it is assumed with $68 \%$ certainty that the true effect of at-issueness will lie between -1 and 0.

- Consistency: Since there was no prior knowledge of consistency on projectivity, a normal prior with mean 0 and standard deviation of 0.5 was chosen which means that the effect of consistency is assumed to lie between -0.5 and 0.5 with a certainty of $68 \%$.

- Standard deviation: For the variance of the model parameters, the default prior of the brms package was used, which is a half student-t prior with 3 degrees of freedom, based on the recommendations by Gelman (2006) and the prior choice recommendations by the stan development team (Stan Development Team, 2018).

Results The model included random effects such as random by-lexical contents intercepts, assuming differences between lexical contents, and random by-lexical content effects slopes for consistency, assuming that the effect of consistency may vary across lexical contents. Further, random by-lexical content effects slopes for at-issueness were included, based on the assumption that also the effect of at-issueness differs between lexical contents. The model was conducted using the beta distribution as likelihood with a logit link, modelling the predictive change of projectivity ratings in log-odds. The model was fitted using 4 chains each with 2000 iterations, whereby 1000 iterations are used as warm up, resulting in 4000 posterior samples in total.

\begin{tabular}{cl|c|c|c|c} 
& & Coefficients & SE & HPDI & PI \\
\hline \hline \multirow{3}{*}{ Model 1 } & Intercept & 0.713 & 0.06 & $(0.69,0.737)$ & $(0.69,0.737)$ \\
& Consistency & 0.05 & 0.27 & $(-0.502,0.587)$ & $(-0.499,0.595)$ \\
& At-issueness & -0.36 & 0.14 & $(-0.634,-0.083)$ & $(-0.641,-0.0866)$
\end{tabular}

Table 3.3: This table summarises the models' output, i.e. fixed effects, standard errors (SE) and $95 \%$ highest posterior density intervals (HPDI) and 95\% percentile interval (PI).

Table 3.3 shows the estimated model parameters, their standard deviations and two $95 \%$ credible intervals, more specifically, highest posterior density intervals (HPDI) and percentile intervals (PI). ${ }^{5}$

\footnotetext{
${ }^{5}$ Credible intervals consist of two parameter values between which $95 \%$ of the posterior probability lies. As such they show the range within which one can be to $95 \%$ certain the true parameter value lies.
} 
The intercept of 0.713 means that when the presupposition of stop is to some extent at-issue (average at-issueness 0.495) and more or less consistent (average consistency measure 0.495) it is on average $71 \%$ likely to project. Furthermore, while the credible intervals for the intercept and the effect of atissueness are fairly narrow, the credible intervals for the effect of consistency are very broad and do not exclude the possibility of a negative effect opposed to the predicted positive effect of consistency. Indeed, the posterior probability that the effect of consistency on projectivity is positive, and thus, greater than zero, $\mathrm{P}(\beta>0)$, is about 0.582 , which is almost at chance level. In contrast, the posterior probability that the effect of at-issueness on projectivity is negative, and thus, less than zero, $\mathrm{P}(\beta<0)$, is 0.995 .

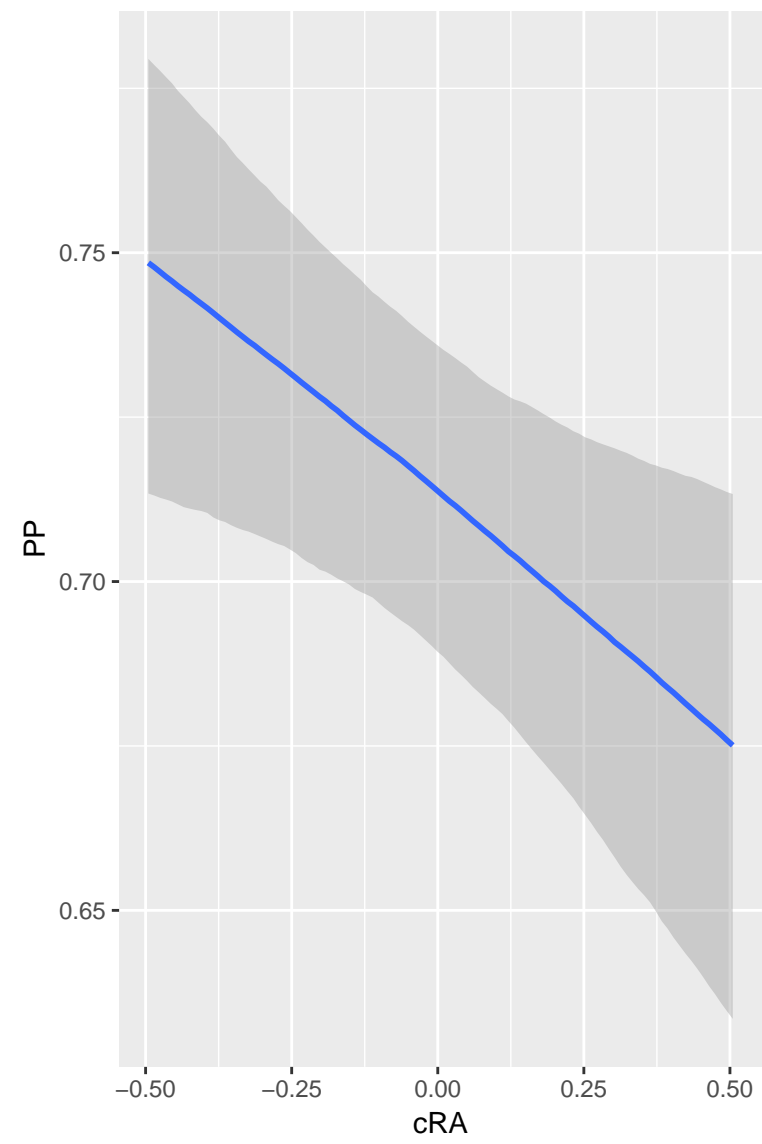

(a)

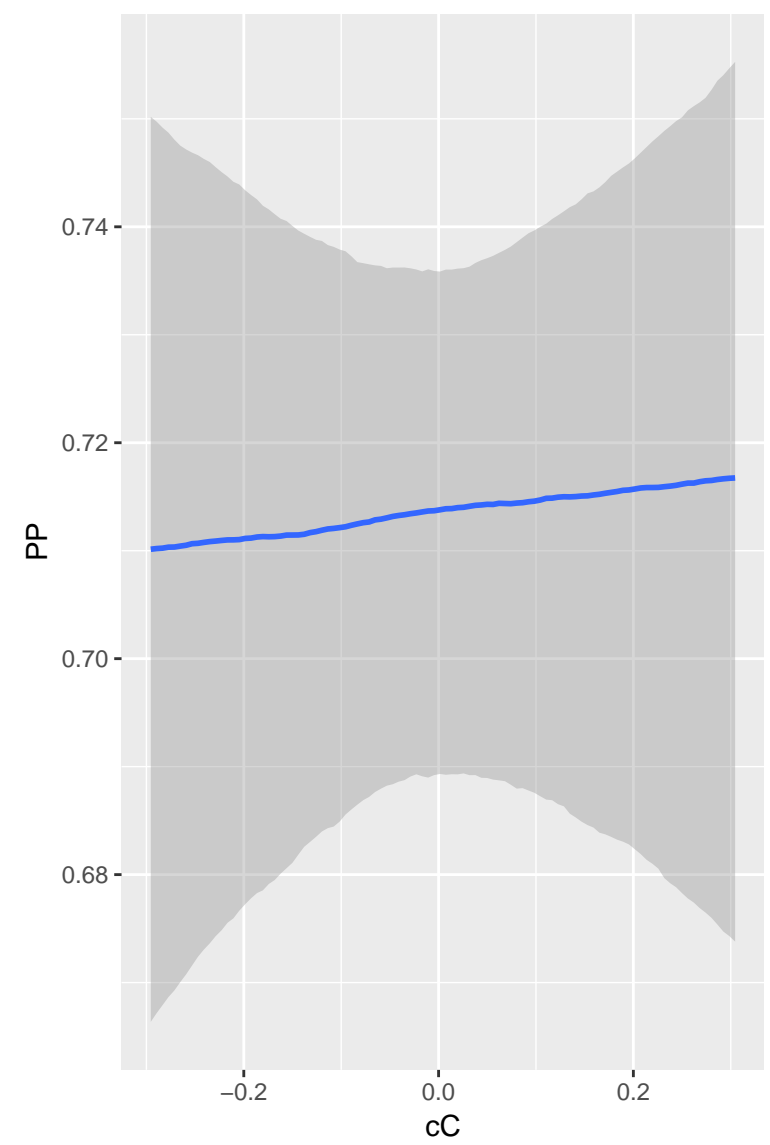

(b)

Figure 3.6: Projectivity ratings as function of at-issueness ratings (a) or consistency (b) averaging over lexical contents. The grey area presents $95 \%$ Credible Intervals.

Figure 3.6 illustrates the effect of at-issueness and consistency on projectivity. The effect of at- 
issueness predicts that when at-issueness of lexical content exceeds its average of 0.459 by 0.4 the probability of the presupposition to project decreases on average by around $3 \%$, as long as the content is fairly consistent with gender stereotypes (average 0.459). The effect of consistency predicts that when consistency of lexical content exceeds its average of 0.459 by 0.4 , the probability that the presupposition projects increases on average by $0.4 \%$, as long as the content is mostly not at-issue (average 0.459).

Prior sensitivity check In order to check in which way the obtained results are influenced by the choice of priors, a second model was conducted which used less informative priors for the intercept and the effect of at-issueness.

- Intercept: A normal distribution was used as prior with mean 0.5 and standard deviation 0.5. This was recommended to use instead of the uniform prior (uniform $(0,1)$ ) when a parameter can be anywhere from 0 to 1 (Stan Development Team, 2018)) and means that the grand mean lies between 0 and 1 with a certainty of $68 \%$.

- At-issueness/Consistency: This time, a normal distribution with mean 0 and standard deviation 0.5 was used as prior for both effects. Which means that the effect is assumed to lie between -0.5 and 0.5 with a certainty of $68 \%$.

- Standard deviation: Similar to the first analysis, for the scale parameters of the model the default prior of the brms package (Bürkner, 2017, in press) was used, which is a half student-t prior with 3 degrees of freedom, based on the recommendations by Gelman (2006) and the prior choice recommendations by the stan development team (Stan Development Team, 2018).

\begin{tabular}{rl|c|c|c|c} 
& & Coefficients & SE & HPDI & PI \\
\hline \hline \multirow{2}{*}{ Model 1 } & Intercept & 0.713 & 0.06 & $(0.69,0.737)$ & $(0.69,0.737)$ \\
& Consistency & 0.05 & 0.27 & $(-0.502,0.587)$ & $(-0.499,0.595)$ \\
& At-issueness & -0.36 & 0.14 & $(-0.634,-0.083)$ & $(-0.641,-0.0866)$ \\
\hline \multirow{2}{*}{ Model 2 } & Intercept & 0.715 & 0.07 & $(0.774,1.064)$ & $(0.685,0.744)$ \\
& Consistency & 0.05 & 0.29 & $(-0.499,0.627)$ & $(-0.508,0.614)$ \\
& At-issueness & -0.32 & 0.14 & $(-0.595,-0.055)$ & $(-0.598,-0.055)$
\end{tabular}

Table 3.4: Fixed effects, standard errors (SE) and 95\% highest posterior density intervals (HPDI) and $95 \%$ percentile interval (PI), repeatedly shown for the first model where informative priors were used, and the second model where non-informative or weakly informative priors were used. 
As can be seen in table 3.4, there is only a slight difference between estimated intercepts and effect sizes of the two models. The effect of at-issueness obtained in the second model is slightly smaller than in the first one, leading to a $2.8 \%$ decrease in projectivity ratings, when at-issueness exceeds it's average by 0.4 , opposed to the $3 \%$ decrease that was estimated before. Likewise, the posterior probabilities are very similar. The posterior probability that the effect of consistency is greater than zero $\mathrm{P}(\beta>0)$ is 0.565 , again, almost at chance level. The posterior probability that the effect of at-issueness is less than zero $\mathrm{P}(\beta<0)$ is about 0.99 which is almost the same as for the model with informative priors. This illustrates that the informative priors that were used for the intercept and the effect of at-issueness did not influence the obtained results to a great extent.

The second analysis within the Bayesian framework made it possible to include random effects slopes. Furthermore, prior knowledge could be taken into account and the model could make reasonable predictions on projectivity ratings ranging from 0 to 1 . In total, this analysis led to similar results as were obtained by the first analysis in section 3.2.2, with a slightly smaller effect of at-issueness on projectivity - a 5.5\% decrease according to the frequentist model versus a 2.8-3\% decrease according to the Bayesian model. Again, consistency did not affect projectivity ratings in a systematic way.

\subsection{Discussion}

\subsubsection{The case of discover}

According to the results, listeners are not less likely to accommodate the presupposition triggered by stop globally when gender stereotypes they may have had a priori are violated. To put it differently, no effect of consistency on projectivity could be found. Does this mean that prior beliefs do not influence the process of understanding presuppositions? One may argue that the absence of an effect of prior beliefs is (i) due to the presupposition of stop itself, such that prior beliefs did not affect the presupposition of stop since it projects too robustly. It may be the case, however, that other, less robust presuppositions, may be influenced by world knowledge. Thus, in order to answer the question positively (or negatively) one has to investigate other presupposition triggers, which

may possibly have less robust projection behaviour. Further, (ii) it can be argued that it is due to the type of prior belief that was tested and that other prior beliefs may have an influence. Recall that Tonhauser et al. (2018); Stevens et al. (2017) did not say anything about gender stereotypes but instead focused on prior probabilities of events such as flying to the moon or flying to New York. In order to test these two claims for future research, a small pilot study with 40 participants was conducted by focusing on discover and investigating the possible differences between flying to the moon versus flying to a plausible location. For this purpose, the same survey was used, only changing the filler item containing discover, see (64) for projectivity block items and (65) 
for at-issueness block items. ${ }^{6}$ The order of items within one block was randomised, whereby the projectivity block preceded the at-issueness block.

(64) a. Did Lisa discover that Dani flew to Amsterdam?

b. Did Martin discover that Alex flew to the moon?

(65) a. Lara: Doreen discovered that Malte flew to Amsterdam.

b. Stanley: Are you sure?

c. Lara: Yes, I'm sure that Malte flew to Amsterdam.

Did Lara answer Stanley's question?

(66) a. Freddie: Paul discovered that Carla flew to the moon.

b. Stanley: Are you sure?

c. Freddie: Yes, I'm sure that Carla flew to the moon.

Did Freddie answer Stanley's question?

A simple linear regression model was fit to the data. Projectivity was modelled as function of centred at-issueness ratings and the binary variable plausible (1) versus implausible (0). The rudimentary analysis revealed that there was again only a significant effect of at-issueness, see 3.5.

\begin{tabular}{l|ccr} 
& Coefficients & SE & t-value \\
\hline \hline Intercept & 0.8598 & 0.03718 & 23.128 \\
At-issueness & -0.18901 & 0.07846 & -2.409 \\
Plausible & 0.0069 & 0.05261 & 0.131
\end{tabular}

Table 3.5: Linear regression model output

As may be observed in the graph 3.7, there is no apparent difference between the items 'flying to Amsterdam' and 'flying to the moon'. At-issueness has the same effect on both conditions. Thus, projectivity was assessed similarly for both lexical contents, no matter whether the lexical content was likely or unlikely. This very small study may suggest that neither the object of investigation, i.e. the presupposition triggered by stop, nor the chosen independent variable, i.e. prior beliefs in form of gender stereotypes, is the reason why there was no significant effect of prior beliefs on projectivity ratings.

\footnotetext{
${ }^{6}$ In contrast to the first experiment, this time the question in the projecvitity block corresponded to the content of the speaker's question.
} 


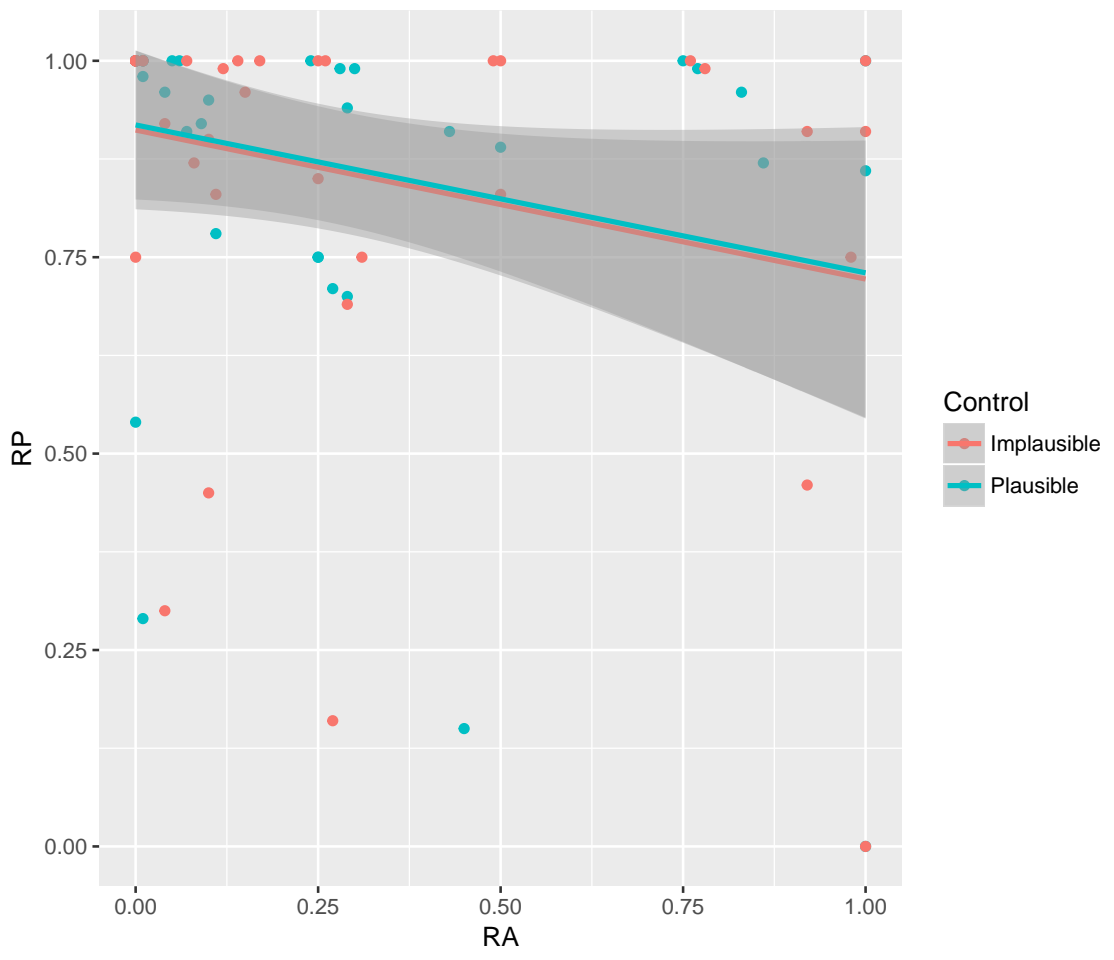

Figure 3.7: This plot illustrates projectivity $(\mathrm{P})$ as function of at-issueness ratings for the presupposition triggered by discover. The less likely event of flying to the moon is illustrated in red, and the more likely event is illustrated in blue.

\subsubsection{Extreme prior probabilities}

Although it seemed tempting to assume that the influence of prior beliefs may explain the variation between lexical contents, it may as well have been an overstatement/over-simplification. There are two explanations for why results were as they were: (i) listeners tend to revise their world knowledge when they encounter utterances that do not agree with their beliefs, and (ii), the effect of prior beliefs have been found to be more solid for production than comprehension. As was illustrated by the scalar implicature example in subsection 2.4.2, prior probabilities of world states may affect their posterior probabilities. To remind the reader, the scenario involved chalks that had disappeared. In the discussed case, Lisa (the listener) had no extreme beliefs about whether one world state was more likely than the others, Johannes could have stolen one $s_{1}$, two $s_{2}$, or three $s_{3}$ chalk sticks. Thus $P\left(s_{3} \mid u_{\text {some }}\right)$ - the posterior probability of $s_{3}$-was lower than $P\left(s_{3}\right)$ - the prior probability of $s_{3}$. What about a case where Lisa knows that Johannes often steals chalk sticks and when he does, he always steals all of them, suggesting $P\left(s_{3}\right)>0.5$ ? The set-up of the standard RSA model entails that extreme priors $(>0.5)$ lead to equally high posterior probabilities. This 
means when the prior probability of $s_{3}$ approaches 1 the posterior probability of $s_{3}$ given $u_{\text {some }}$ approaches 1: $P\left(s_{3} \mid u_{\text {some }}\right) \rightarrow 1$ as $P\left(s_{3}\right) \rightarrow 1$. Thus, the influence of $u_{\text {some }}$ disappears and with it the scalar implicature. Evidently, this goes against our intuitions that some would nonetheless give rise to a scalar implicatures. Degen et al. (2015) investigated this issue further by collecting prior and posterior probabilities of events. They showed that even if participants judged an event like marbles sinking in water as being highly likely, the utterance some of the marbles sank gave rise to a scalar implicature. Thus, listeners were found to revise their world knowledge - their extreme prior beliefs - when they process utterances that do not correspond to their world knowledge. It is possible that this is what was found here: although listeners' may have strong prior beliefs about gender stereotypes, they may revise their beliefs temporarily when they read an utterance like Sebastian stopped working as a nanny.

These findings are strongly linked with a general tendency that world knowledge or context effects are more likely to be investigated in production tasks instead of comprehension tasks. As was already mentioned, Boyce et al. (2018) found only a gender bias against female pronouns in their production task. Similarly, Degen et al. (2015) did not find effects of extreme prior beliefs at the interpretation level. Moreover, Degen and Goodman (2014)'s findings illustrate that the effect of contextual information, manifested by different questions under discussions, may get more robustly apparent in production-like tasks (e.g. word probability ratings) than in comprehension-like tasks (e.g. sentence interpretation). Since this thesis mainly investigates presupposition projection from a listener's perspective, exploiting participants' comprehension of presuppositions instead of their production, may mean that world knowledge effects are not tractable by using an interpretation task.

\subsubsection{The task}

The claim made in the previous section and the data patterns found in this study goes well with the claim that the task may not be sufficient to investigate the influence of listeners' prior beliefs on their understanding of presuppositions. The data showed large variability between responses which gets most evident by taking a closer look at the results of the two control items in (67), see 3.6.

a. Is Tim a vegetarian?

Maria is a vegetarian. // Are you sure? // Yes, I'm sure that Maria is a vegetarian.

b. Did Johanna bring cookies?

Titus brought cookies. // Are you sure? // Yes, I'm sure that Titus brought cookies.

The response similarities between these two control items suggest that they were broadly understood in the same way as was intended. But for both items, the standard deviations of projectivity ratings were very large, suggesting that there was nonetheless a great deal of variation. One may argue 
to exclude those participants that gave ratings that are, for example, two standard deviations above or below the mean, since one could argue that these participants used different response strategies. However, this would have reduced the data set substantially, and furthermore, there was no evident response pattern by observing single participants that could have additionally justified such a decision.

\begin{tabular}{l|c|c|r} 
Item & Response & Mean & SD \\
\hline \hline Vegetarian & Projectivity & 14.44394 & 19.38941 \\
Vegetarian & At-issueness & 95.00915 & 13.84531 \\
Cookie & Projectivity & 14.43249 & 19.89844 \\
Cookie & At-issueness & 95.88787 & 11.48608
\end{tabular}

Table 3.6: Controls

That the task itself opened up a wide scope of response strategies gets apparent by participant comments, submitted at the end of the questionnaire. For example, some comments suggested that participants primarily tried to concentrate on the correctness of the sentences without thinking about plausibility. Further, the missing context and missing prosodic cues inevitably led to assigning focus individually. This was considered and wanted, since it was tested whether participants who found content more at-issue, and as such may have placed the focus as follows: Did Sebastian stop working as a $N A N N Y$ ?, also found that content to be less projective. However, it may have induced a lot of confusion. Participants commented that they felt uncertain about their responses, since the questions of the projectivity block were found to be ambiguous because one could pronounce the question in different ways. Hence it is not clear whether projection variability is based on the feeling of uncertainty about the task or reflects the degree to which participants found the speaker to be certain/uncertain. All this suggests that in order to explore the influence of prior knowledge on listeners' interpretation of presuppositions further, a more fine grained experimental design is needed.

\subsection{Conclusion}

Back to the set of predictions that was outlined during the course of this thesis, findings on projection variability suggest that the presupposition triggered by stop, despite being highly projective, can be suspended. Against the claims of Heim (1983), the presupposition was not always globally accommodated. Recall that presuppositions that are new to listeners are predicted to be globally accommodated when there is no local context, such as explicit denial or ignorance contexts, that 
could license local accommodation. Findings on the effect of at-issueness agree with the Gradient Projection Principle (Tonhauser et al., 2018). Thus, against the restrictive predictions by Simons et al. (2016), not only the presupposition of factives is influenced by at-issueness. When it comes to the predictions by Abrusán (2011, 2016), projection variability suggests that the presupposition triggered by stop may be suspended, which goes against Abrusán (2016)'s claim. Since this thesis only focused on the presupposition trigger stop, no claims can be made about the predictive ordering of Abrusán (2016).

When it comes to the proposed effect of world knowledge, prior beliefs in form of gender stereotypes could not explain the variation between lexical contents as was suggested. Similar to Tonhauser et al. (2018)'s study, at-issueness could only explain some of the observed projection variability. It remains to be investigated whether the variability of projectivity ratings that could not be explained by at-issueness is due to the task or the characteristics of stop. As was pointed out throughout this thesis, stop has often been a deviating case which resulted in varying claims about its projectivity. Nonetheless, preliminary results of the pilot study on discover suggested that it is not simply about stop projecting robustly and being immune against the effects of priors. Further research is needed with a more fine-grained design to explore projectivity and possible influence factors further. 


\section{Abbreviations}

\section{Local contexts (2.1)}

\begin{tabular}{l|l} 
Abbreviation & Explanation \\
\hline \hline $\mathrm{C}$ & context (overall context of utterances) \\
$C+S$ & operation: applying the CCP of S to C \\
$\mathrm{CCP}$ & context change potential \\
$\mathrm{C} \& p s p(\mathrm{~S})$ & operation: add psp $(\mathrm{S})$ to C \\
$\operatorname{psp}(\mathrm{S})$ & presupposition of S \\
$\mathrm{S}$ & (simple) sentence/ atomic formula \\
$\mathrm{w}$ & worlds
\end{tabular}

Discourse structure (2.2)

\begin{tabular}{l|l} 
Abbreviation & Explanation \\
\hline \hline A & answer \\
$\mathrm{a}$ & entity \\
$\mathrm{F}$ & focus \\
{$[\ldots]_{F}$} & focused expression \\
$\mathrm{H}^{*}$ & high tone pitch accent \\
$\mathrm{L}+\mathrm{H}^{*}$ & complex pitch accent \\
$\mathrm{p}$ & proposition \\
$\mathrm{P}$ & property \\
$\mathrm{Q}$ & question \\
QUD & question under discussion
\end{tabular}


Attention and variability (2.3)

\begin{tabular}{l|l} 
Abbreviation & Explanation \\
\hline \hline $\mathrm{C}$ & context \\
{$[\ldots]_{F}$} & focused expression \\
$\mathrm{p}$ & intuitive entailment of a sentence $\mathrm{S}$ \\
$\mathrm{p}$ & alternative of $\mathrm{p}$ \\
$\mathrm{S}$ & sentence \\
$\mathrm{S}$ & alternative of $\mathrm{S}$ \\
$\mathrm{t}$ & time interval
\end{tabular}

World knowledge (2.4)

\begin{tabular}{l|l} 
Abbreviation & Explanation \\
\hline \hline $\mathrm{C}(\mathrm{u})$ & utterance costs \\
$\mathrm{L}_{0}$ & literal listener \\
$\mathrm{L}_{1}$ & pragmatic listener \\
$\mathrm{n}$ & number \\
$\mathrm{RSA}$ & Rational Speech Act model \\
$\mathrm{S}$ & Set of possible worlds \\
$\mathrm{S}_{1}$ & speaker \\
$\mathrm{S}$ & world state \\
$\mathrm{U}$ & set of utterances \\
$\mathrm{u}$ & utterance
\end{tabular}

Experiment (3.1)

\begin{tabular}{l|l} 
Abbreviation & Explanation \\
\hline \hline $\mathrm{AE}$ & American English \\
$\mathrm{BE}$ & British English
\end{tabular}




\section{Results (3.2)}

\begin{tabular}{l|l} 
Abbreviation & Explanation \\
\hline \hline CI & Confidence Interval \\
HPDI & Highest Posterior Density Interval \\
PI & Percentile Interval \\
SE & Standard Error
\end{tabular}

\section{Discussion (3.3)}

\begin{tabular}{l|l} 
Abbreviation & Explanation \\
\hline \hline RSA & Rational Speech Act model \\
S & Set of possible worlds \\
S & world state \\
SD & standard deviation \\
SE & Standard Error \\
$\mathrm{u}$ & utterance
\end{tabular}




\section{Appendix}

\subsection{Experiment}

\begin{tabular}{c|l|l|c|l|c|c} 
Item & Occupation & Bias & Code & Name & Consistency & Consistent \\
\hline \hline 1 & plumber & male & -1 & male & 0.8 & 1 \\
1 & plumber & male & 1 & female & 0.2 & 0 \\
2 & nanny & female & -1 & male & 0.2 & 0 \\
2 & nanny & female & 1 & female & 0.8 & 1 \\
3 & beautician & female & -1 & male & 0.21 & 0 \\
3 & beautician & female & 1 & female & 0.79 & 1 \\
4 & butler & male & -1 & male & 0.78 & 1 \\
4 & butler & male & 1 & female & 0.22 & 0 \\
5 & blacksmith & male & -1 & male & 0.77 & 1 \\
5 & blacksmith & male & 1 & female & 0.23 & 0 \\
6 & manicurist & female & -1 & male & 0.24 & 0 \\
6 & manicurist & female & 1 & female & 0.76 & 1 \\
7 & barber & male & -1 & male & 0.75 & 1 \\
7 & barber & male & 1 & female & 0.25 & 0 \\
8 & ballet dancer & female & -1 & male & 0.27 & 0 \\
8 & ballet dancer & female & 1 & female & 0.73 & 1 \\
9 & janitor & male & -1 & male & 0.71 & 1 \\
9 & janitor & male & 1 & female & 0.29 & 0 \\
10 & librarian & female & -1 & male & 0.31 & 0 \\
10 & librarian & female & 1 & female & 0.69 & 1
\end{tabular}

Table 3.7: Manipulation and corresponding consistency measure (1-10) 


\begin{tabular}{c|l|l|c|l|c|c} 
Item & Occupation & Bias & Code & Name & Consistency & Consistent \\
\hline \hline 11 & police officer & male & -1 & male & 0.68 & 1 \\
11 & police officer & male & 1 & female & 0.32 & 0 \\
12 & florist & female & -1 & male & 0.33 & 0 \\
12 & florist & female & 1 & female & 0.67 & 1 \\
13 & architect & male & -1 & male & 0.64 & 1 \\
13 & architect & male & 1 & female & 0.36 & 0 \\
14 & interior decorator & female & -1 & male & 0.37 & 0 \\
14 & interior decorator & female & 1 & female & 0.63 & 1 \\
15 & lawyer & male & -1 & male & 0.6 & 1 \\
15 & lawyer & male & 1 & female & 0.4 & 0 \\
16 & designer & female & -1 & male & 0.42 & 0 \\
16 & designer & female & 1 & female & 0.58 & 1 \\
17 & bartender & male & -1 & male & 0.57 & 1 \\
17 & bartender & male & 1 & female & 0.43 & 0 \\
18 & cashier & female & -1 & male & 0.45 & 0 \\
18 & cashier & female & 1 & female & 0.55 & 1 \\
19 & musician & male & -1 & male & 0.54 & 1 \\
19 & musician & male & 1 & female & 0.46 & 0 \\
20 & translator & female & -1 & male & 0.47 & 0 \\
20 & translator & female & 1 & female & 0.53 & 1 \\
& & & & &
\end{tabular}

Table 3.8: Manipulation and corresponding consistency measure (11-20) 


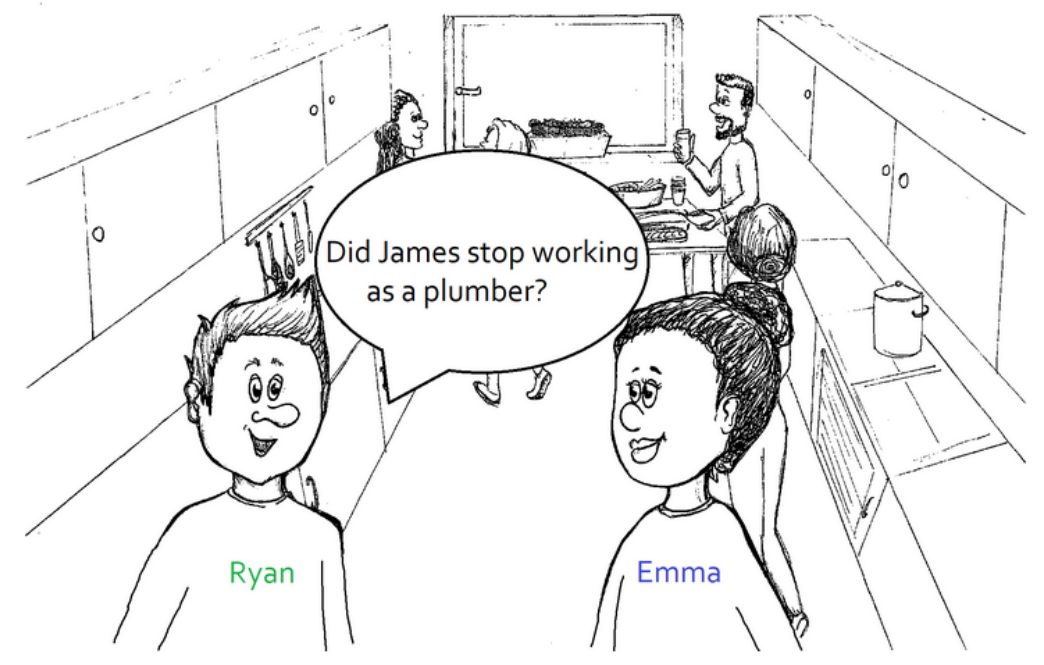

Is Ryan certain that James used to work as a plumber?

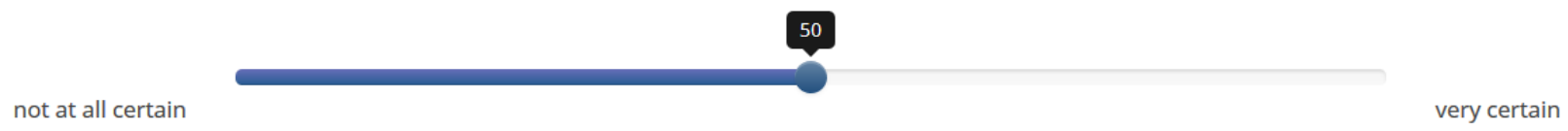

Figure 3.8: Experimental item for 'plumber'/male (Projectivity) 

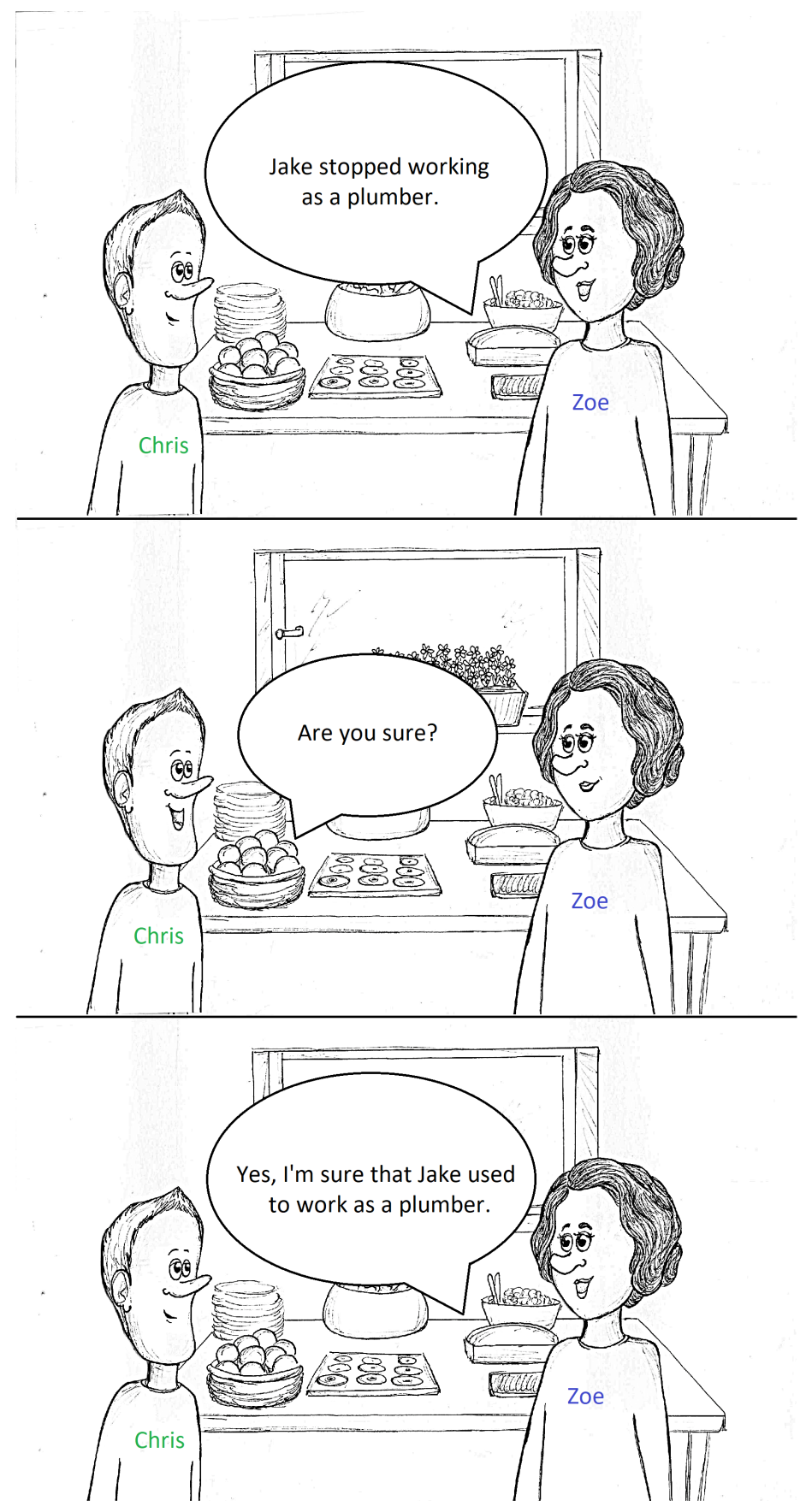

Did Zoe answer Chris's question?

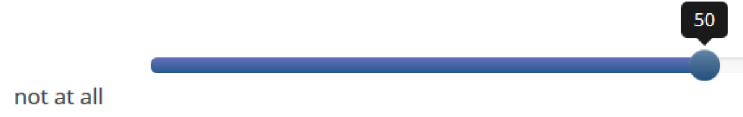

definitely yes

Figure 3.9: Experimental item for 'plumber'/male (At-issueness) 


\subsection{Analysis 1}

\subsubsection{Residuals}

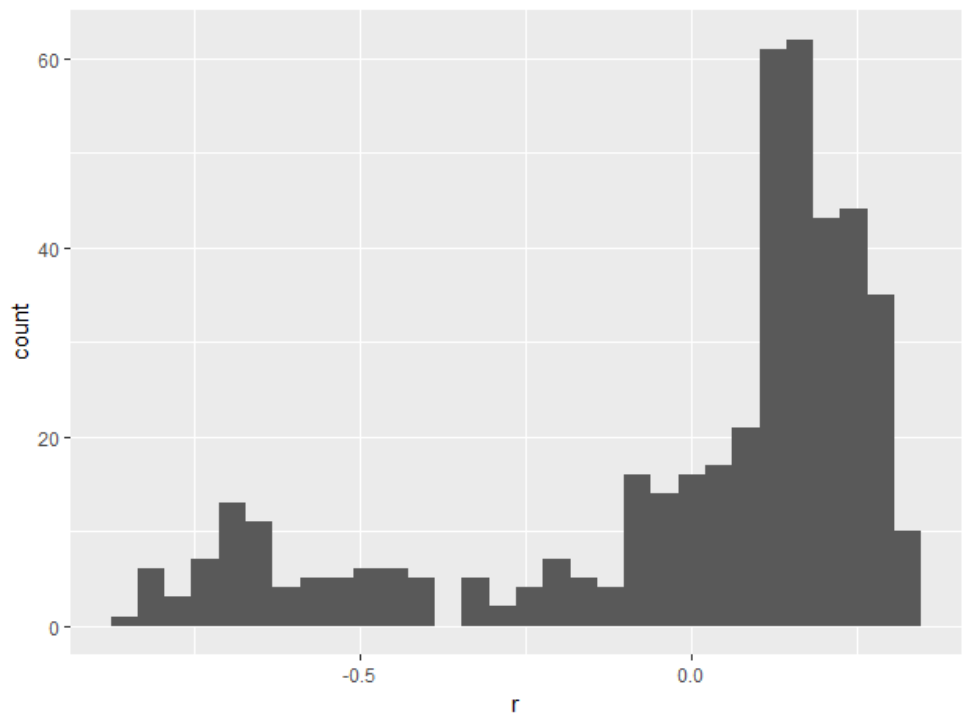

Figure 3.10: Normality diagnostics for residuals

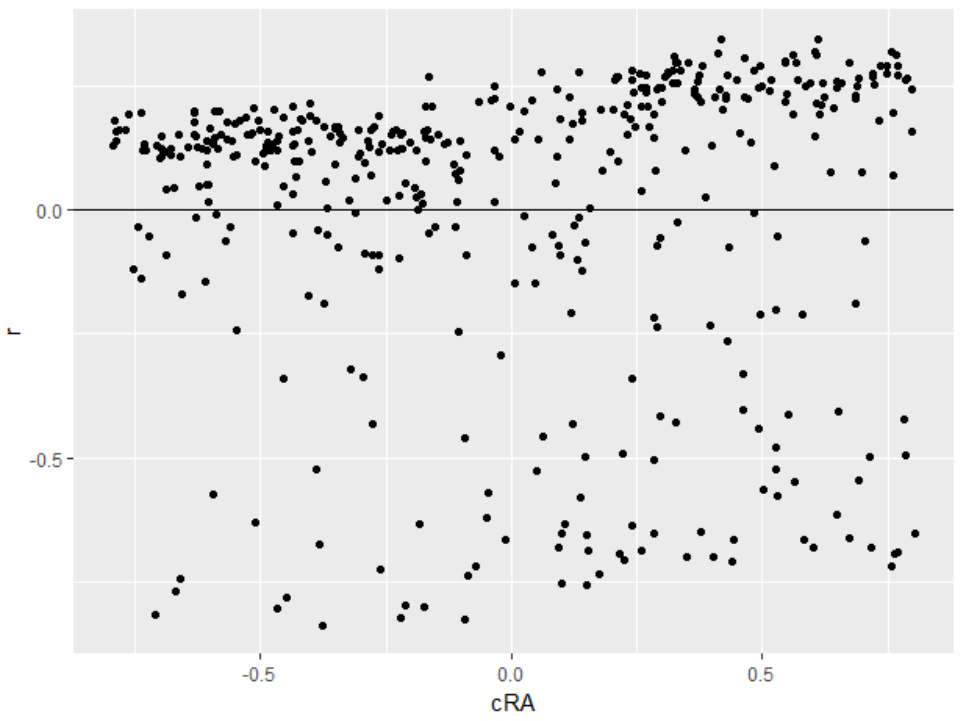

Figure 3.11: Equal variance diagnostics for residuals of fixed effect 'At-issueness' 


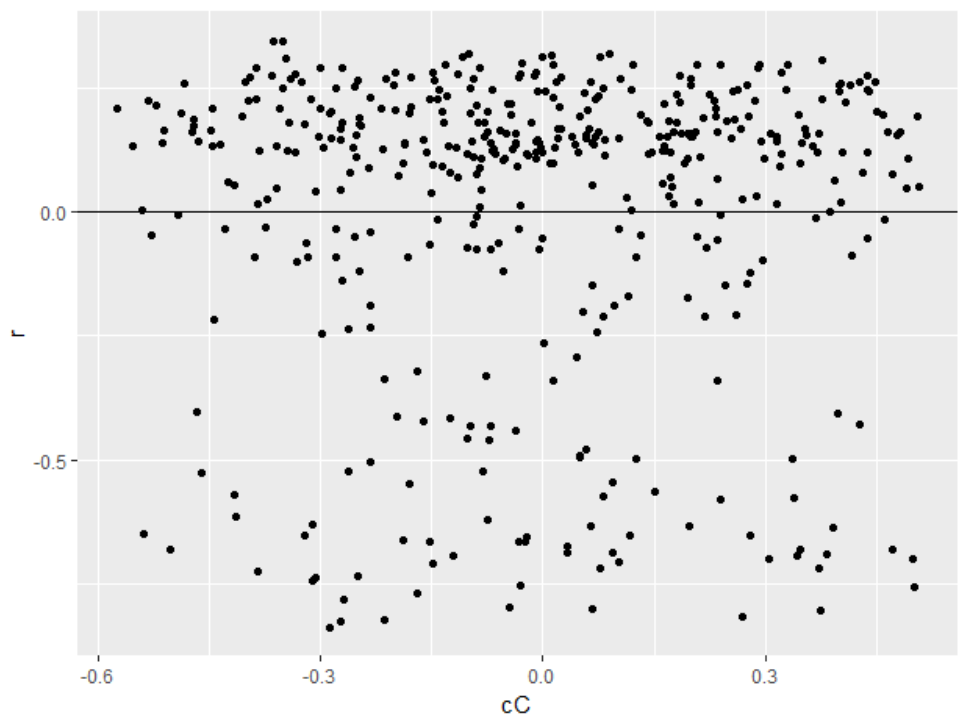

Figure 3.12: Equal variance diagnostics for residuals of fixed effect 'Consistency'

\subsubsection{Normality of random effects}

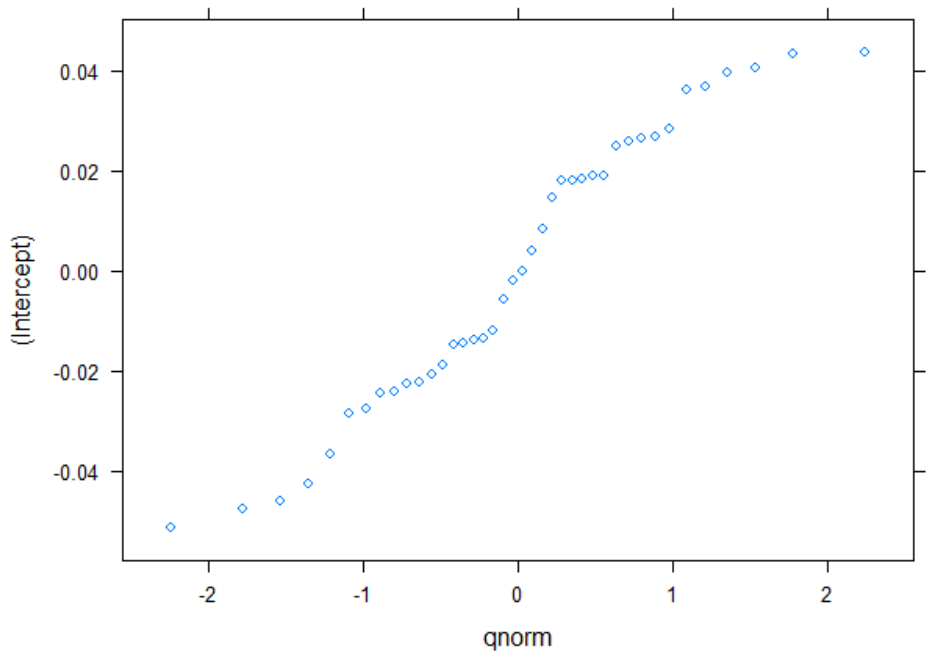

Figure 3.13: Normality diagnostics for by-lexical content random intercepts 


\subsubsection{Bootstrap}
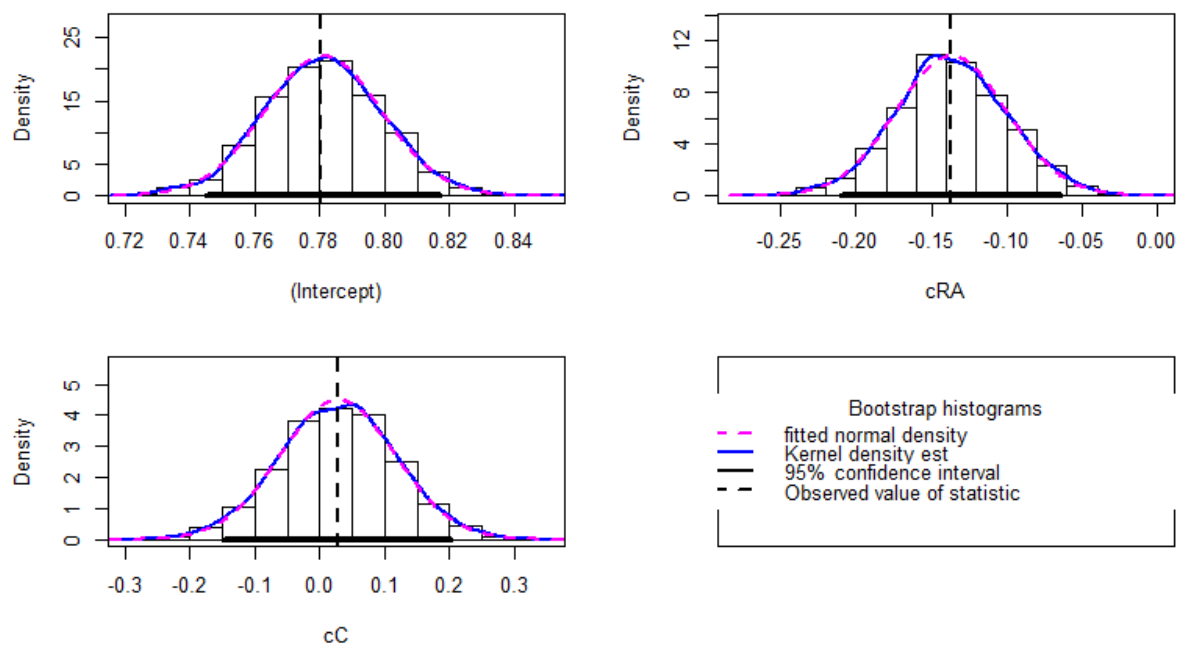

Figure 3.14: Histograms for bootstrapped coefficients, together with the normal density based on the bootstrap mean and standard deviation (blue red dashed line). The dashed vertical line shows the original point estimates and the thick horizontal line shows the $95 \%$ interval. 


\section{References}

Abbott, B. (2000). Presuppositions as nonassertions. Journal of Pragmatics, 32(10), 1419-1437.

Abrusán, M. (2011). Predicting the presuppositions of soft triggers. Linguistics 83 Philosophy, 34 , $491-535$.

Abrusán, M. (2016). Presupposition cancellation: Explaining the 'soft-hard' trigger distinction. Natural Language Semantics, 24, 165-202.

Abusch, D. (2010). Presupposition triggering from alternatives. Journal of Semantics(27), 37-80.

Bates, D., Mächler, M., Bolker, B. \& Walker, S. (2015). Fitting linear mixed-effects models using lme4. Journal of Statistical Software, 67(1), 1-48.

Beaver, D. (2010). Have you noticed that your belly button lint colour is related to the colour of your clothing? In R. Bäuerle, U. Reyle \& E. Zimmermann (Eds.), Presuppositions and Discourse: Essays offered to Hans Kamp (pp. 65-99). Elsevier.

Boyce, V., von der Malsburg, T., Poppels, T. \& Levy, R. (2018, mar). Implicit gender biases in the production and comprehension of pronominal references. In F. Ferreira, J. Henderson, T. Swaab \& M. Traxler (Eds.), Proceedings of the 31th Annual CUNY Conference on Human Sentence Processing. Davis, CA, USA: UC Davis.

Bürkner, P.-C. (2017). brms: An R package for Bayesian multilevel models using Stan. Journal of Statistical Software, 80(1), 1-28. doi: M10.18637/jss.v080.i01

Bürkner, P.-C. (in press). Advanced Bayesian multilevel modeling with the $\mathrm{R}$ package brms. The $R$ Journal.

Canty, A. \& Ripley, B. D. (2017). boot: Bootstrap r (s-plus) functions [Computer software manual]. ( $\mathrm{R}$ package version 1.3-20)

Chemla, E. \& Bott, L. (2013). Processing presuppositions: Dynamic semantics vs pragmatic enrichment. Language and Cognitive Processes, 38(3), 241-260.

Chierchia, G. \& McConnell-Ginet, S. (2000). Meaning and Grammar: An Introduction to Semantics. MIT Press.

Cribari-Neto, F. \& Zeileis, A. (2010). Beta regression in R. Journal of Statistical Software, 34(2), 1-24. Retrieved from Mhttp://www.jstatsoft.org/v34/i02/ 
Cummins, C., Amaral, P. \& Katsos, N. (2013). Backgrounding and accommodation of presuppositions: An experimental approach. In E. Chemla, V. Homer \& G. Winterstein (Eds.), (Vol. 17, pp. 201-218).

Cummins, C. \& Rohde, H. (2015). Evoking context with contrastive stress: Effects on pragmatic enrichment. Frontiers in Psychology, 6, 1779.

Davison, A. C. \& Hinkley, D. V. (1997). Bootstrap methods and their applications. Cambridge: Cambridge University Press.

Degen, J. \& Goodman, N. D. (2014). Lost your marbles? The puzzle of dependent measures in experimental pragmatics. In Proceedings of the 36th Annual Meeting of the Cognitive Science Society, CogSci 2014, Quebec City, Canada, July 23-26, 2014.

Degen, J., Tessler, H. \& Goodman, N. D. (2015). Wonky worlds: Listeners revise world knowledge when utterances are odd..

Ferrari, S. \& Cribari-Neto, F. (2004). Beta regression for modelling rates and proportions. Journal of Applied Statistics, 31(7), 799-815.

Fox, J. \& Weisberg, S. (2011). Bootstrapping Regression Models in R. In An R Companion to Applied Regression (second ed., pp. 41-58). Thousand Oaks CA: Sage. (last modified October 2017)

Franke, M. \& Jäger, G. (2016). Probabilistic pragmatics, or why Bayes' rule is probably important for pragmatics. Zeitschrift für Sprachwissenschaft, 35(1), 3-44.

Gelman, A. (2006). Prior distributions for variance parameters in hierarchical models. Bayesian Analysis, 1, 1-19.

Geurts, B. (1995). Presupposing (Unpublished doctoral dissertation). University of Stuttgart.

Goodman, N. D. \& Frank, M. C. (2016). Pragmatic Language Interpretation as Probabilistic Inference. Trends in Cognitive Sciences, 20(11), 818-829.

Goodman, N. D. \& Stuhlmüller, A. (2012). Knowledge and Implicature: Modeling Language Understanding as Social Cognition. Topics in cognitive science, 5, 173-184.

Grice, P. H. (1975). Logic and conversation. In P. Cole \& J. L. Morgan (Eds.), Syntax and Semantics 3: Speech Acts (pp. 41-58). Academic Press.

Halekoh, U. \& Højsgaard, S. (2014). A kenward-roger approximation and parametric bootstrap methods for tests in linear mixed models - the $\mathrm{R}$ package pbkrtest. Journal of Statistical Software, 59(9), 1-30.

Heim, I. (1983). On the projection problem for presuppositions. In M. Barlow, D. Flickinger \& N. Wiegand (Eds.), Proceedings of WCCFL 2 (pp. 114-125). Stanford University.

Jackendoff, R. S. (1972). Semantic Interpretation in Generative Grammar. MIT Press.

Kadmon, N. (2001). Formal pragmatics. Oxford: Blackwell.

Karttunen, L. (1971). Some Observations on Factivity. Papers in Linguistics(5), 55-69. 
Karttunen, L. (1974). Presupposition and linguistic context. Theoretical Linguistics(1), 181-194.

Levinson, S. (1983). Pragmatics. Cambridge University Press.

Limesurvey, G. (2003-2018). LimeSurvey: An Open Source survey tool. Mhttp://www.limesurvey . org. Hamburg, Germany.

Morris, J. S. (2002, February). The BLUPs are not \&quot;best\&quot; when it comes to bootstrapping. Statistics 8 Probability Letters, 56(4), 425-430.

Potts, C. (2005). The Logic of Conventional Implicatures. Oxford: Oxford University Press.

R Development Core Team. (2008). R: A Language and Environment for Statistical Computing [Computer software manual]. Vienna, Austria.

Roberts, C. (1996). Information structure: Towards an integrated formal theory of pragmatics. In J. H. Yoon \& A. Kathol (Eds.), OSU WPL Vol. 49: Papers in Semantics.

Romoli, J. \& Schwarz, F. (2015). An experimental comparison between presuppositions and indirect scalar implicatures. In F. Schwarz (Ed.), Experimental perspectives on presuppositions (pp. 200-209). Chamb: Springer International Publishing.

Schwarz, F. (2016). Presuppositions, projection, and accommodation - theoretical issues and experimental approaches..

Simons, M. (2001). On the conversational basis of some presuppositions. In R. Hastings, B. Jackson \& Z. Zvolenszky (Eds.), (pp. 309-327). Ithaca, NY: CLC Publications.

Simons, M., Tonhauser, J., Beaver, D. \& Roberts, C. (2010). What projects and why. In N. Li \& D. Lutz (Eds.), (Vol. 20, pp. 309-327). Ithaca, NY: Cornell University.

Simons, M., Tonhauser, J., Beaver, D. \& Roberts, C. (2016). The Best Question: Explaining the Projection Behavior of Factives. Discourse Processes, 54(3), 187-206.

Smithson, M. \& Verkuilen, J. (2006). A Better Lemon Squeezer? Maximum-Likelihood Regression With Beta-Distributed Dependent Variables. Psychological Methods, 11(1), 54-71.

Stalnaker, R. (1974). Pragmatic presuppositions. Semantics and Philosophy, 197-214.

Stalnaker, R. (1978). Assertion. In P. Cole (Ed.), Syntax and semantics 9: Pragmatics (Vol. 9, pp. 315-332). Academic Press.

Stan Development Team. (2018). Prior Choice Recommendations. Mhttps://github.com/stan -dev/stan/wiki/Prior-Choice-Recommendations. (Online; accessed 27-July-2018)

Stevens, J., de Marneffe, M.-C., Speer, S. R. \& Tonhauser, J. (2017). Rational use of prosody predicts projection in manner adverb utterances. In Proceedings of the 39th Annual Meeting of the Cognitive Science Society, CogSci 2017, London, UK, 16-29 July 2017.

Strawson, P. F. (1950). On referring. Mind, 59, 320-344.

Sturt, P. (2003). The time-course of the application of binding constraints in reference resolution. Journal of Memory and Language, 48, 542-562.

Tonhauser, J. (2016). Prosodic cues to presupposition projection. Semantics and Linguistic Theory 
XXVI, 934-960.

Tonhauser, J., Beaver, D. \& Degen, J. (2018). How projective is projective content? Gradience in projectivity and at-issueness. Journal of Semantics.

Tonhauser, J., Beaver, D., Roberts, C. \& Simons, M. (2013). Toward a Taxonomy of Projective Content. Language, 89(1), 66-109.

von der Malsburg, T., Poppels, T. \& Levy, R. (2017). Gender bias in linguistic preferences during the 2016 U.S. presidential campaign.

Wickham, H. (2009). ggplot2: Elegant graphics for data analysis. Springer-Verlag New York.

Zeevat, H. (1992). Presupposition and accommodation in update semantics (Vol. 9). 


\section{List of Tables}

2.1 Experimental stimuli . . . . . . . . . . . . . . . . . . . . 21

3.1 Experimental manipulation . . . . . . . . . . . . . . . . . 37

3.2 Model and bootstrap output . . . . . . . . . . . . . . . . . 46

3.3 Bayesian analysis output . . . . . . . . . . . . . . . . 49

3.4 Contrast informative and non-informative priors . . . . . . . . . . 51

3.5 Linear regression model output . . . . . . . . . . . . . . . . . 53

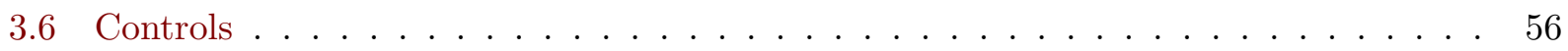

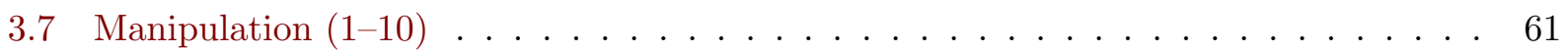

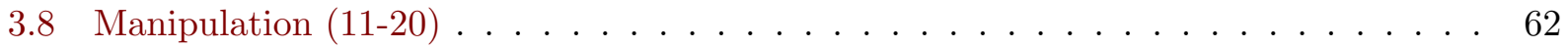




\section{List of Figures}

3.1 Experimental item for 'plumber'/female (Projectivity) . . . . . . . . . . . . . 39

3.2 Experimental item for 'plumber'/female (At-issueness) . . . . . . . . . . . . . 40

3.3 Projectivity Variation . . . . . . . . . . . . . . . . 43

3.4 Projectivity Ratings per lexical content . . . . . . . . . . . . . . . . . 44

3.5 Projectivity Ratings . . . . . . . . . . . . . . . . . . 45

3.6 Projectivity Ratings Bayesian . . . . . . . . . . . . . . . . 50

3.7 Projectivity Discover . . . . . . . . . . . . . . . . . . . 54

3.8 Experimental item for 'plumber'/male (Projectivity) . . . . . . . . . . . . . 63

3.9 Experimental item for 'plumber'/male (At-issueness) . . . . . . . . . . . . . . 64

3.10 Normality diagnostics for residuals . . . . . . . . . . . . . . . . 65

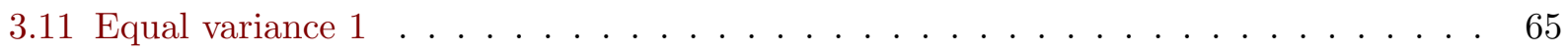

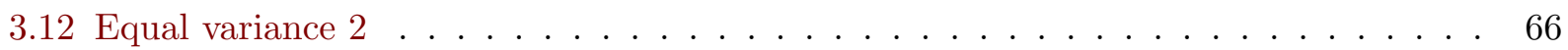

3.13 Normality diagnostics for random effects . . . . . . . . . . . . . . 66

3.14 Bootstrap histogram . . . . . . . . . . . . . . . . . . . 67 